\title{
SPAZI MONASTICI A BENEVENTO
}

\section{MARCELLO ROTILI}

UDC: 726.71(450.725)"653"

Review

Manuscript received: 31. 10. 2016.

Revised manuscript accepted: 07. 02. 2017.

DOI: 10.1484/J.HAM.5.113717
M Rotili

Dipartimento di Lettere e Beni culturali Università della Campania "Luigi Vanvitelli" Via R. Perla 81055-Santa Maria Capua Vetere Caserta, Italia marcello.rotili@unicampania.it

During the Middle Ages, the urban structure of Benevento was characterized by the presence of many churches and monasteries, located in crucial areas of the city, enclosed by walls built in the fourth century as part of the reconstruction and reorganization process. Indeed, after damages due to a strong earthquake, in $346 \mathrm{AD}$, and because of new defense needs due to both international and domestic political plight in the third century, to readapting the walls was mandatory and not delayable. From a critical analysis of documents, it turns out that about ten monastic institutions were located in the city limits, from the north-eastern area to the so-called 'Civitas Nova', from the 'Insula episcopalis' to the area close to the Trajan's arch (which the medieval texts call 'Porta Aurea', i.e. the Golden Gate). However, also outside the city walls, along the main roads, such as Via Appia and Traiana, the presence of monastic centers is well documented. The most part of churches and monasteries is largely attributable to decisions of Dukes of Benevento, who probably ran the urban space, land, labor and production through the real estates of those religious complexes, some of which became important and renowned in culture preservation and transmission. Noteworthy, thanks to accumulated wealth and to the devotion of Lombard aristocracy, monasteries were able to play, at least in some cases, a significant role in the political scene.

Keywords: monastries, churches, Middle Ages, Benevento.

1. Nell'alto medioevo il tessuto urbano di Benevento (figg. 1, 42-43) appare caratterizzato da una densa maglia di chiese e di monasteri dislocati nei settori nevralgici della città che era racchiusa dalle mura costruite nel IV secolo nell'ambito di una vasta opera di ricostruzione-ristrutturazione avviata per porre riparo ai danni del disastroso terremoto del 346 e per adeguare la struttura urbana alle esigenze di difesa poste dalla difficile situazione di politica sia internazionale sia interna determinatasi nel III secolo'. Allora le città italiane (e non solo quelle) furono costrette a munirsi di quelle difese che avevano avuto in età repubblicana ma che erano state demolite o comunque disattivate nel periodo espansivo dello stato imperiale romano, allorché le imprese militari si svolgevano a grande distanza dall'Italia. Dopo la costruzione delle mura aureliane di Roma si registra quella delle mura di Bologna ${ }^{2}$ e di diversi altri centri urbani.

Dall'esame delle fonti scritte e materiali relative a Benevento risulta una decina di istituzioni monastiche (maschili e femminili), ubicate nel perimetro urbano: dall'area nord-orientale alla Civitas nova, dalla zona vicina all'insula episcopalis a quella prossima all'arco di Traiano (la Port'Aurea delle fonti medievali). Sedi monastiche sono altresì note anche nel comprensorio extra moenia, lungo i principali assi viari, quali le vie Appia e Traiana.
Si tratta di fondazioni in buona parte riconducibili alla committenza ducale beneventana che evidentemente gestiva lo spazio urbano, il territorio, il lavoro e la produzione anche attraverso questi complessi religiosi provvisti di patrimoni fondiari che progressivamente erano stati loro attribuiti per scelte di natura sia religiosa che economico-sociale e che risultavano adeguati al loro sostentamento. Divenuti centri illustri di conservazione e di trasmissione culturale (in particolare alcuni), grazie alle ricchezze accumulate, nonché sedi della devozione dell'aristocrazia longobarda, i monasteri riuscirono a giocare in taluni casi, attraverso $\mathrm{i}$ propri abati, un significativo ruolo nello scenario politico.

2. Nell'area di porta Somma si trovavano San Giovanni di Porta Somma (alla quale fanno riferimento due atti, del febbraio 1131 e del luglio 1137³) ed il monastero di Santa Maria di Porta Somma ${ }^{4}$ (fig. 1 n. 2); sull'ubicazione di quest'ultimo in prossimità delle mura di cinta e del luogo sul quale sarebbe stata costruita la Rocca dei Rettori pontifici della città (fig. 2) si esprime Falcone Beneventano nel narrare per il 1121 di una controversia fra Agnese, badessa del monastero di San Pietro di dentro, e la badessa di Santa Maria Bethlem a van-

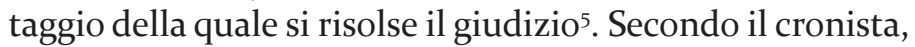
Santa Maria doveva esistere già intorno alla metà dell'VIII

\footnotetext{
${ }^{1}$ Cfr. M. ROTILI, Considerazioni su Benevento nella Tarda antichità, in Aristocrazie e società fra transizione romano-germanica e alto medioevo, Atti del convegno internazionale di studi (Cimitile-S. Maria Capua Vetere, 14-15 giugno 2012), Napoli, 2015, p. 317-351, a p. 317, 337-343 e la bibliografia ivi cit. ${ }^{2} \mathrm{~S}$. GELICHI, La città altomedievale nelle sue strutture materiali, in G. P. Brogiolo, S. Gelichi (eds.), La città nell'alto medioevo italiano. Archeologia e storia, Bari, 2007, p. 45-101, a p. 45, 55-58, 67.

${ }^{3}$ Archivio Storico Provinciale, Benevento (= ASP-BN), Fondo S. Sofia, XIII, 1,4; Repertorium omnium bullarum [...] quae sunt in Archivio Abbatialis Ecclesiae S. Sophiae, ASP-BN, Fondo S. Sofia, ms 21 (= Repertorium S.S.), c. 78a; Index seu registrum omnium instrumentorum Rev.di Capituli Beneventani, ac scripturarum et quam plurimorum memorandorum positorum in Bibliotheca [...] per abbatem Baldassarem Pacillum canonicum, ms., 1628 , Biblioteca Capitolare di Benevento (= Index Pacilli), 354, c. 7 b.

${ }^{4}$ M. ROTILI, Benevento romana e longobarda. L'immagine urbana, Napoli-Ercolano, 1986, p. 91-92.

${ }_{5}^{5}$ FALCONE DI BENEVENTO, Chronicon Beneventanum. Città e feudi dei Normanni, E. D’Angelo (ed.), Firenze, 1998 (= Chronicon Beneventanum), $1121.7 .1-$ 1121.7.15, 64-67; indirizza per l'ubicazione nei pressi del muro di cinta anche ASP-BN, Fondo S. Pietro, VI, 2, settembre 1137. La sentenza rigettò le pretese di supremazia giurisdizionale da parte del monastero di San Pietro decretando la piena autonomia di Santa Maria alla quale venne conferito il privilegio della dipendenza dalla Sede apostolica.
} 


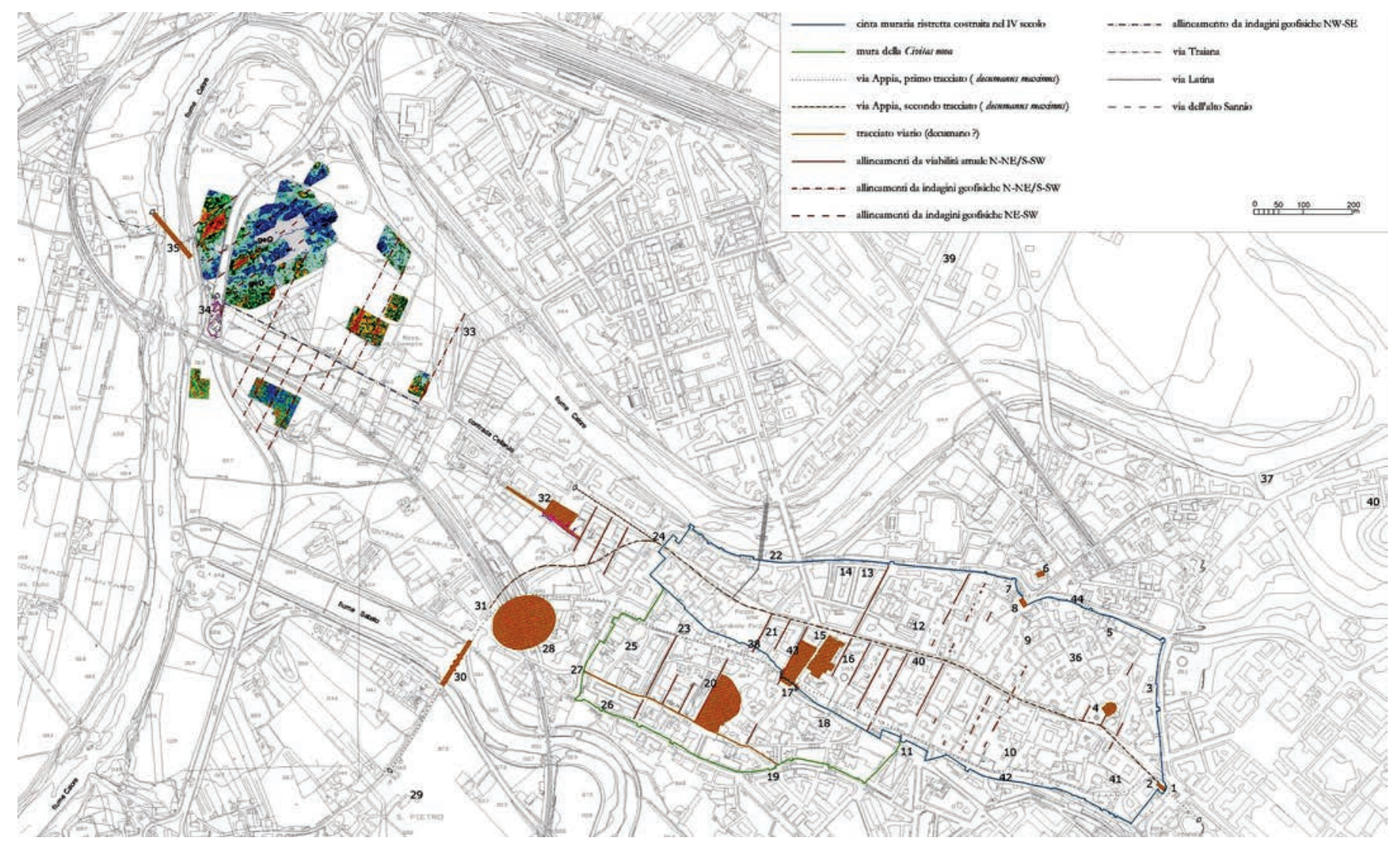

Fig. 1. Benevento e area di Cellarulo, planimetria con restituzione grafica delle indagini geodiagnostiche e ricostruzione della città tardoantica: 1. Porta Somma con fortilizio nella Rocca dei Rettori; 2. Chiesa e monastero di S. Maria di Porta Somma, nei pressi chiesa di S. Giovanni di Porta Somma; 3. Chiesa e Xenodochio di S. Benedetto ad Caballum, nei pressi del «loco Caballo»; 4. Chiesa e monastero di S. Sofia; 5. Chiesa di S. Pietro ad Caballum e, nella zona, chiesa di S. Angelo de Caballo; 6. Chiesa e monastero di S. Ilario a Port'Aurea; 7. Chiesa e monastero di S. Giovanni a Port'Aurea; 8. Arco di Traiano, Port'Aurea; 9. Chiesa di S. Matteo a Port'Aurea e, nella zona, chiesa di S. Angelo a Port'Aurea; 10. Monastero di S. Vittorino; 11. Porta Rufina; nei pressi chiese di S. Artellaide e S. Renato, ecclesiae S. Benedicti de adobbatoris detta più tardi de scalellis e S. Nicolay de suburbio, platea puplica vicino alla chiesa di S. Renato; 12. Zona delle chiese di S. Mauro e S. Costanzo; 13. Monastero di S. Adeodato; nei pressi chiesa di S. Gregorio; 14. Monastero di S. Paolo, «secus murum huius beneventanae civitatis", "erga trasendam puplicam que dicitur de Leone iudice»; 15. Platea puplica recta; nei pressi casa di Dacomario con torre e pontile e altro pontile; a non grande distanza, quasi certamente nella Civitas nova, chiesa di S. Giovanni de fabricatoribus; 16. Cattedrale e basilica di S. Bartolomeo apostolo de Episcopio; 17. Arco del Sacramento, porta della cinta di IV secolo; 18. Chiesa e monastero di S. Modesto; 19. Porta Nova; nei pressi, chiesa di S. Nazzaro de lutifiguli; 20. Teatro, nei pressi monastero dei Ss. Lupulo e Zosimo; vicino trasenda e "platea puplica, qui descendit ad porta que dicitur de Hiscardi»; 21. Ecclesia S. Stephani de monialibus de Foro, nei pressi ecclesia S. Jacobi a Foro; 22. Ponte di S. Onofrio, nei pressi il monastero e chiesa di S. Onofrio e le chiese di S. Maria a Porta Gloriosa e di S. Angelo de Porta Gloriosa; 23. Chiesa dei Ss. Filippo e Giacomo; nei pressi trasenda dei Calderari; chiese di S. Tecla e S. Secondino; 24. Porta S. Lorenzo; nei pressi chiesa e monastero di S. Lorenzo; 25. Edificio termale; nei pressi ecclesia S. Bartholomei in thermis; 26. Torre con arco di porta romana, identificabile con la Turris Pagana; nei pressi ecclesia S. Nicolay Turris Paganae; 27. Port'Arsa-Porta Liscardi; al n. 76 di via Torre della Catena, edificio romano sul cui muro perimetrale è fondato il muro di cinta della Civitas nova; 28. Anfiteatro; 29. Monastero di S. Pietro fuori le mura; 30. Ponte Leproso; 31. Chiesa di S. Cosma; 32. Edificio romano detto «I Santi Quaranta» dal titolo dell'omonima chiesa; 33. Area del porto fluviale; 34. Quartiere artigianale, area degli scavi archeologici; 35. Pons Maior-Ponte Fratto; 36. Piazza Piano di Corte, area del Sacrum Palatium; nei pressi chiesa di S. Stefano de Neophitis, detta anche di S. Stefano de Iudeca o de plano Curiae; 37. Monastero di S. Sofia a Ponticello; piu avanti, lungo la via Traiana diretta a Brindisi, si trovava la chiesa di S. Valentino, all'altezza del ponte romano che da essa prendeva il nome; 38. In piazza cardinal Pacca, monastero di S. Pietro de monachabus sulle strutture di un edificio forse di tipo termale; nei pressi resti di un acquedotto romano; 39. Chiesa di S. Marciano; 40. Xenodochio e chiesa di S. Michele Arcangelo "que constructa esse videtur foras hanc cibitate $(m)$ ultra porta $(m)$ Aurea $(m)$, trans ipso ponticello frabito»; 41. Monastero del SS. Salvatore, "propinquo trasenda publica, que discendit ad porta Rufini»; 42. Monastero di Sant'Eufemia; 43. "Arco di S. Gennaro", pontili; vicino la chiesa di S. Festo; 44. Sottofondazione del muro di cinta del IV secolo realizzata dopo il sisma del 1125 in prossimità dell'ex convento di S. Agostino.

secolo come cella del monastero di San Pietro intra muros, al quale sarebbe stata assoggettata tra il 751 e il 758 dal duca Liutprando; ma il primo documento disponibile riguarda la chiesa di Santa Maria «que sita est int(er) duas vias foras ante porta Summa cum p(ro)pria terra sua que dicitur domnica» che nel novembre 774 fu concessa da Arechi II al monastero di Santa Sofia ${ }^{6}$. Il cenobio è attestato per la prima volta da un atto del 1086 relativo all'acquisto di una vigna e di alcuni castagneti da parte della badessa Lavinia ${ }^{7}$ in località Sali- cetum presso San Marco ai Monti e vide crescere la propria potenza economica (di cui avevano posto le premesse proprio le due badesse prima ricordate) fra XII e XIII secolo: ai numerosi possedimenti nel contado beneventano e nell'alto Sannio se ne aggiunsero diversi in Puglia e soprattutto nella baronia di Trevico.

Il declino, tra fine XIII-inizi del XIV secolo, comportò che papa Bonifacio VIII, l'8 giugno 1302, costatata espressamente la crisi spirituale e materiale del monastero, decretasse, con

${ }^{6}$ J.-M. Martin (ed.), Chronicon Sanctae Sophiae, cod. Vat. Lat. 4939, studio dell'apparato decorativo di G. Orofino, Roma, 2000 (Fonti per la storia dell'Italia medievale, Rerum Italicarum Scriptores, 3) (= Chronicon Sanctae Sophiae), I, 64, p. 333-334.

${ }^{7}$ ASP-BN, Fondo S. Pietro, XXVIII, 3. Cfr. inoltre E. JAMISON, The abbes Bethlem of S. Maria di Porta Somma and the barons of the Terra Beneventana, in Oxford essays on mediaeval history presented to H.E. Salter, Oxford, 1934, p. 33-67, a p. 61. 
la bolla Inter ceteras sollicitudines, che le monache fossero aggregate al monastero delle clarisse di San Lorenzo ${ }^{8}$. Infine nel 1321 papa Giovanni XXII dispose la soppressione del cenobio e il trasferimento delle monache nel monastero di San Pietro intra moenia che avvenne il 26 aprile 1323 ad opera dell'arcivescovo Monaldo Monaldeschi ${ }^{9}$. Dalle strutture del monastero venne ricavato il palazzo annesso alla nuova sede fortificata dei rettori pontifici ${ }^{10}$ che non erano più al sicuro dalle insidie dei baroni del regno e da quelle dei beneventani stessi nell'ormai fatiscente palatium che era stato la sede dei principi longobardi sin da quando Arechi II lo aveva strutturato rinnovando la corte dei duchi ricavata molto probabilmente nel praetorium di età romana alla fine del VI o agli inizi del VII secolo. Il complesso, edificato su disposizione del pontefice e del successore Benedetto XII dal rettore de Balaeto, fu progettato su modelli provenzali ed eseguito a partire dal 1321 da magister Melus o Meulus e da magister Landulphus" la $^{\mathrm{I}}$ Rocca superstite ed il palazzo, sostituito nel XVIII secolo dall'edificio costruito in adiacenza al mastio che ne incorporò $\mathrm{i}$ resti (fig. 2), erano racchiusi da un muro di cinta raffigurato in età moderna da alcuni artisti.

La strada che da porta Somma conduceva alla porta Rufini è attestata da una concessione dei principi Landolfo I e Atenolfo II del 22 febbraio 926 al «monasterio Domini Salvatoris quod constructum esse videtur infra hanc beterem Beneventanam civitatem secus trasenda que pergit ad portam Rufini $»^{12}$. Sull'ubicazione del cenobio, menzionato (come femminile) per la prima volta

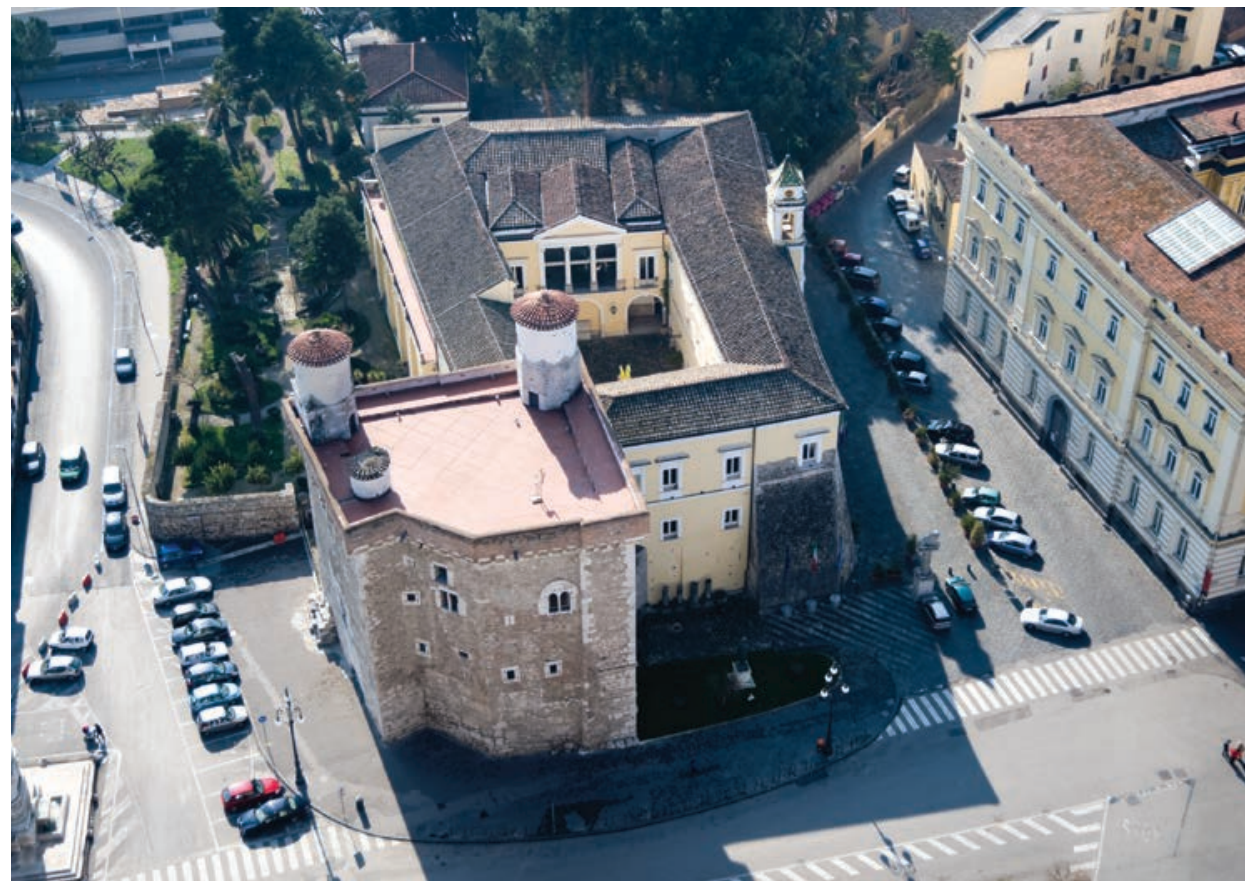

Fig. 2. Benevento, Rocca dei Rettori.

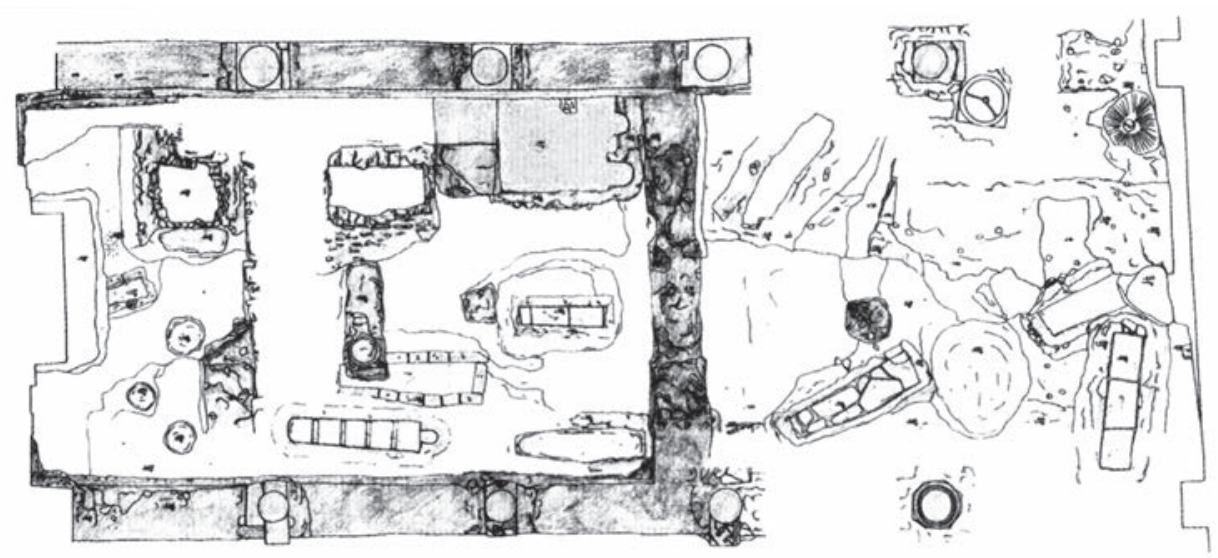

Fig. 3. Benevento, Chiesa del SS. Salvatore, pianta di scavo.

dall'atto appena citato, in adiacenza all'attuale chiesa di San Salvatore in via Stefano Borgia, retrostante il Palazzo

\footnotetext{
${ }_{8}^{8}$ G.G. Sbaraglia (ed.), Bullarium Franciscanum Romanorum Pontificum constitutiones, epistolas ac diplomata continens tribus ordinibus Minorum, Clarissarum et Poenitentium a seraphico patriarcha Sancto Francisco institutis concessa ab illorum exordio ad nostra usque tempora, IV, Roma, 1759-68, p. 552-553 n. 233; A. POTTHAST, Regesta Pontificum Romanorum inde ab anno post Christum natum 1198 ad annum 1304, Berolini, 1874-75, n. 25157; A. ZAZO, Il castello di Benevento, Napoli, 1954, p. 10 nota 29.

9 Il mandato di papa Giovanni XXII del 22 settembre 1321 al rettore Guglielmo de Balaeto, in S. BORGIA, Memorie istoriche della pontificia città di Benevento, II, Roma, 1764, p. 189-193, conferma la corrispondenza fra Santa Maria di Porta Somma e la Rocca dei Rettori. Cfr. al riguardo P.F. Kehr, W. Holtzmann (eds.), Italia pontificia, Regesta Pontificum. Romanorum, IX. Samnium, Apulia, Lucania, Berlin, 1962, p. 103, ov’è detto: «A. 1323 aprii. 26 Guillelmus de Balaeto civitatis Beneventanae rector ex mandato lohannis XXII a. 1321 sept. 22 sub anulo piscatoris sibi directo moniales S. Mariae de Porta summa ad mon. S. Petri cum omnibus bonis transtulit et in loco ipsius monasterii Portae summae castrum pro conservatione civitatis et rectoris habitatione extruere fecit, quod etiam hodie superest».

10 Index Pacilli, op. cit. (n. 3), 354, 14: «Cum in loco monasterii monialium sancte Marie de porta summa Beneventani ordinis sancti Benedicti quoddam quoddam Castrum pro habitatione Rectoris [...] construi et edificari mandemus, discrecioni tue per apostolica scripta committimus et mandamus, quatenus Abbatissam et Conventum Monialium eiusdem Monasterii sancte Marie ad Monasterium Monialium sancti Petri Beneventanum dicti ordinis, si earum capax existit, ibidem cum Conventu Monialium eiusdem Monasterii sancti Petri perpetuis temporibus dominio servientes, auctoritate nostra transferre procures». Cfr. inoltre S. BORGIA, op. cit. (n. 9), p. 189-193; G. MOLLAT (ed.), Lettres communes des papes d'Avignon. Jean XXII (1316-1334), Paris,1933, n. 16084; A. ZAZO, op. cit. (n. 8), p. 10-11.

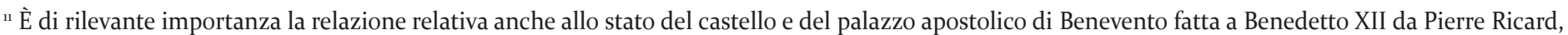
tesoriere della città pontificia, nel 1336: edito da Ė.G. LEONARD, Une description du chateau de Bénévent sous le pontificat de Bénoit XII, in Samnium, IV, 1931, p. 17-22 e poi da G. MOLLAT, Construction d'une fortresse a Bénévent, sous le pontificat de Jean XXII et de Bénoit XII, in Melanges d'archéologie et d'histoire, 62, 1950, p. 149-164, il rapporto è riportato nel ms. lat. 5913 della Bibliothèque Nationale de France, Paris, contenente documenti della Camera Apostolica di Avignone relativi al Regno di Sicilia. Sull'edificazione della Rocca dei Rettori cfr. M. ROTILI, Per il piano del centro storico di Benevento: recupero e salvaguardia degli strati medievali, in Archeologia medievale, 6, 1979, p. 215-231, a p. 228-229.

${ }^{12}$ A. Ciaralli, V. De Donato, V. Matera (eds.), Le più antiche carte del Capitolo della Cattedrale di Benevento (668-1200), Roma, 2002 (Fonti per la storia dell'Italia medievale. Regesta Chartarum, 52) (= Le più antiche carte del Capitolo), n. 7, p. 21-23, a p. 22.
} 




a

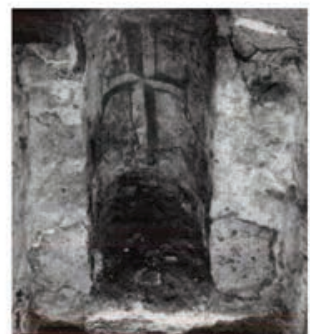

b

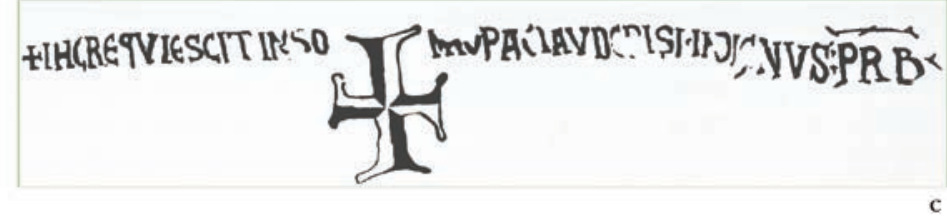

Fig. 4. Benevento, Chiesa del SS. Salvatore: $a-b$, tomba à logette del presbitero Auderisio; $c$, rilievo grafico dell'iscrizione dipinta.



Fig. 5. Benevento, Chiesa del SS. Salvatore, prospetto della facciata.

della Prefettura (fig. 1 n. 41; 11), non vi può essere dubbio: i dati archeologici risultanti dagli scavi degli anni 1997-99, nell'indicare la complessa stratigrafia del sito la cui prima occupazione risale al VII secolo, confermano che la chiesa fu costruita tra VIII e IX secolo, epoca alla quale va datata la tomba (caratterizzata da un profondo incavo per l'alloggiamento della testa) di un presbitero che l'iscrizione dipinta in rosso indica essere stato Auderisio: IHC REQVIESCIT IN

SOMNO PACI AVDERISI INDIGNUS PRB ${ }^{13}$ (figg. 3-4). La sepoltura risulta essere stata utilizzata per un secondo individuo, mentre i manufatti rinvenuti (croce in osso con intagli campiti in rosso e due nappine di fibre tessili intessute di filo d'oro e d'argento, pertinenti alla cintura dell'abito, sono da correlare al primo inumato e cioè Auderisio. Nella chiesa è stata scavata una seconda tomba dello stesso tipo, ma bisoma e con doppio alloggiamento per il capo. L'ubicazione, alcune centinaia di metri più a valle nei pressi di porta Rufina, proposta con perentoria sicurezza ${ }^{14}$, oltre ad essere contraddetta dall'indicazione di un anonimo erudito (anni 1664-68) che colloca il monastero presso il giardino delle monache di San Vittorino (distante, comunque, qualche centinaio di metri da Porta Rufina e meno lontano della porta dalla chiesa di via Stefano Borgia), risulta priva di fondamento: infatti la documentazione relativa alla consacrazione nel 1161, da parte dell'arcivescovo Enrico ${ }^{15}$, di un'ecclesia $S$. Salvatoris che la platea antiqua Sanctae Sophiae indica come ecclesia S. Salvatoris de Porta Summa ${ }^{16}$ e che sarebbe stata edificata da Alberto, decano di Santa Sofia ${ }^{17}$ si riferisce molto probabilmente ad un'altra fondazione a meno che non alluda ad una riconsacrazione dopo una ricostruzione (enfatizzata per scopi encomiastici) in seguito ai danni prodotti dal terremoto del 22 gennaio 1139, successivo a quello, più grave, dell'11 ottobre $1125^{18}$.

Gli scavi hanno peraltro confermato la forma quadrata a due navate delimitate da quattro colonne con absidi, individuata in base a una notizia d'archivio $^{19}$ e all'osservazione dall'esterno della parete di fondo e della facciata (fig. 5), forma che sembra rinviare alla fine dell'epoca longobarda; per le proporzioni San Salvatore doveva richiamare la cappella di San Felice in Felline presso Salerno ${ }^{20}$. Vicina ad ambiente bizantino e datata all'XI secolo, questa costruzione offre un efficace riscontro all'ipotesi di datazione della chiesa beneventana al X secolo, quando è documentata. A Benevento un impianto come quello del San Salvatore è attestato pure dalla chiesa di Santo Stefano de Neophitis, detta anche di Santo Stefano de Iudeca o de plano Curiae per la vicinanza al serralium ebraico a sud-ovest del Piano di Corte ${ }^{21}$ (fig. 1 n. 36). Di datazione incerta, l'edificio misurava m 11,75x11 e non era molto più grande

\footnotetext{
${ }^{13}$ L. TOMAY, Benevento longobarda: dinamiche insediative e processi di trasformazione, in G. D’Henry, C. Lambert (eds.), in Atti del convegno “Il popolo dei Longobardi meridionali (570-1076): testimonianze storiche e monumentali", Salerno 28 giugno 2008, p. 119-147, a p. 128-130.

${ }^{14}$ C. LEPORE, “Monasticon Beneventanum”. Insediamenti monastici di regola benedettina in Benevento, in Studi beneventani, 6, 1995, p. 25-168, a p. 135-137; C. LEPORE, R. VALLI, “Turris quae vocatur contena”: la torre della catena di Benevento, in Studi beneventani, 4-5, 1991, p. 75-134, a p. 87.

${ }^{15}$ N. PARISIO, Pergamene già appartenenti alla famiglia Fusco ed ora acquistate dalla Società Napoletana di Storia Patria, in Archivio Storico per le Province Napoletane, 8, 1883, 2, p. 153-161, 332-338, a p. 336 n. 14.

${ }^{16}$ Platea antiqua Sanctae Sophiae usque ad annum 1382, ASP-BN, Fondo S. Sofia, manoscritti, vol. 58, c. 118a.

${ }^{17}$ ASP-BN, Fondo S. Sofia, XIII 12, XIII 13: «Albertus decanus bone memorie monasterii sancte Sophiae [...] nuper construxit quandam ecclesiam vocabulo domini Salvatoris». Va anche registrata l'ipotesi che la nobile famiglia Maccabeo abbia avuto lo ius patronatus della chiesa, al riguardo cfr. A. ZAZO, Le chiese parrocchiali di Benevento del XII-XIV secolo, in Samnium, 32, 1959, p. 6o-83, a p. 81-82 n. 87.

${ }^{18}$ E. Boschi (ed.), Catalogo parametrico dei terremoti italiani, Bologna, 1999, p. 27 nn. 34, 33.

${ }^{19}$ Cfr. Acta et decreta Ill.mi et Rev.mi D. Vincentii Nuccii Eugubinii V.S.D. Prothonotarij Apostolici et in civitate et Diocesi Beneventana sede Archiepiscopali vacante ob mortem Eminentissimi Cardinalis Oreggij, 1640, Biblioteca Apostolica Vaticana, XXXII, 155, Cod. Barb. Lat. 2364.

${ }^{20}$ M. ROTILI, I monumenti della Longobardia meridionale attraverso gli ultimi studi, in Atti del Convegno internazionale sul tema «La civiltà dei Longobardi in Europa», Roma-Cividale del Friuli, 24-28 maggio 1971, Roma, 1974, p. 203-239, p. 235 e la bibliografia ivi cit.

${ }^{21}$ G. DE NICASTRO, Benevento sacro, Benevento, 1683, ms., Benevento, Pubblica Biblioteca Arcivescovile «F. Pacca», G. Intorcia (ed.), Benevento, 1976, p. 293.
} 
del San Salvatore che aveva il lato di $\mathrm{m} 10^{22}$. Il rinvio ad un insediamento ebraico contenuto nel titolo della chiesa di Santo Stefano, come in quello delle chiese di San Nazzaro e di San Gennaro de Iudeca, ubicate nella zona a sud-ovest del Sacrum Palatium (fig. 1 n. 36) introduce il problema della presenza a Benevento nell'alto medioevo di comunità orientali $^{23}$ cui fanno riferimento anche le chiese dette de Grecis ${ }^{24}$.

Al periodo longobardo rimanda la dedicazione al Salvatore cui erano intitolate molte chiese: oltre alla cappella ubicata nel Sacrum Palatium di Benevento, la chiesa e monastero del San Salvatore di Brescia, costruito su committenza dell'ultimo re longobardo Desiderio e della regina Ansa (suoceri di Arechi II) probabilmente nel 753, la chiesa di San Salvatore di Sirmione e il San Salvatore di Leno edificati sempre per volontà di Desiderio e Ansa. L'edificio beneventano venne ristrutturato nel 1650 ricevendo l'assetto a tre navate col quale è pervenuto, mentre nuovi lavori vennero eseguiti dopo il terremoto del 5 giugno 1688.

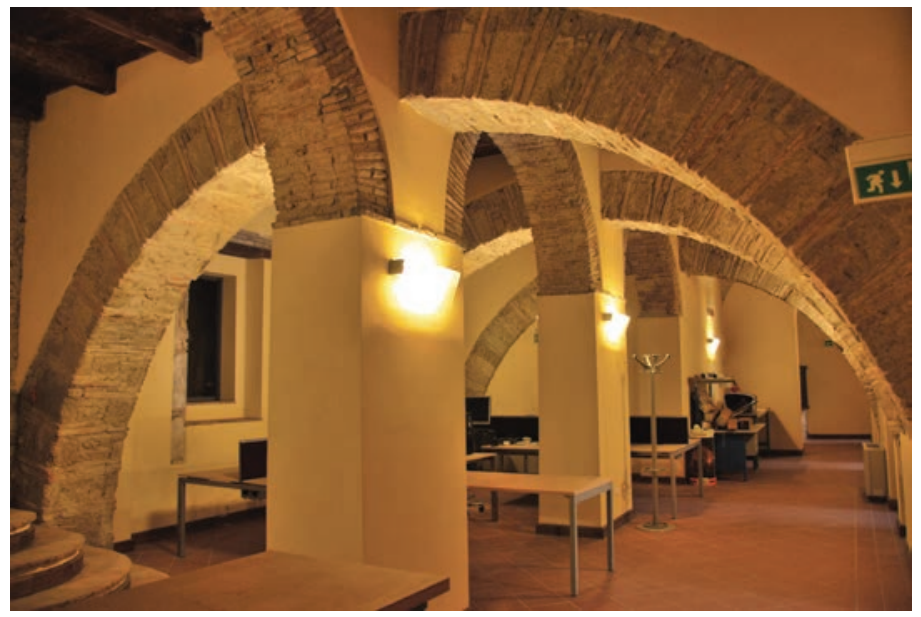

Fig.6. Benevento, ex monastero di S. Vittorino, ora sede di un Dipartimento dell'Università degli Studi del Sannio, archi in tufi e laterizi.
3. Sul versante meridionale del colle della Guardia racchiuso dalle mura di cinta del IV secolo, oltre a quello di San Salvatore erano i monasteri di Sant'Eufemia (fig. 1 n. 42), risalente almeno alla fine dell'VIII secolo se fu oggetto di una concessione di Grimoaldo IV del gennaio $808^{25}$, e di San Vittorino (figg. 1 n. 10; 10-11), di cui restano numerose strutture costituite fra l'altro da archi in tufi e mattoni (figg. 6-9) la cui datazione è compatibile con la cronologia indicata dalle fonti. Documentato nell'aprile $1016^{26}$, questo cenobio si era formato molto probabilmente prima, per iniziativa delle monache di San Salvatore di Alife: scampate al saccheggio e all'incendio del loro monastero compiuto dai Saraceni negli anni di governo del principato di Benevento e Capua da parte di Atenolfo I (che morirà nel 910) e del figlio Landolfo I (che governerà fino al 643 in associazione col fratello Atenolfo II), trovarono rifugio presso la chiesa di Santa Croce, ubicata all'esterno di porta Somma (fig. 1 n. 1). Il testo del Chronicon Vulturnense ${ }^{27}$, nell'indicare che esse, dopo avervi abitato per

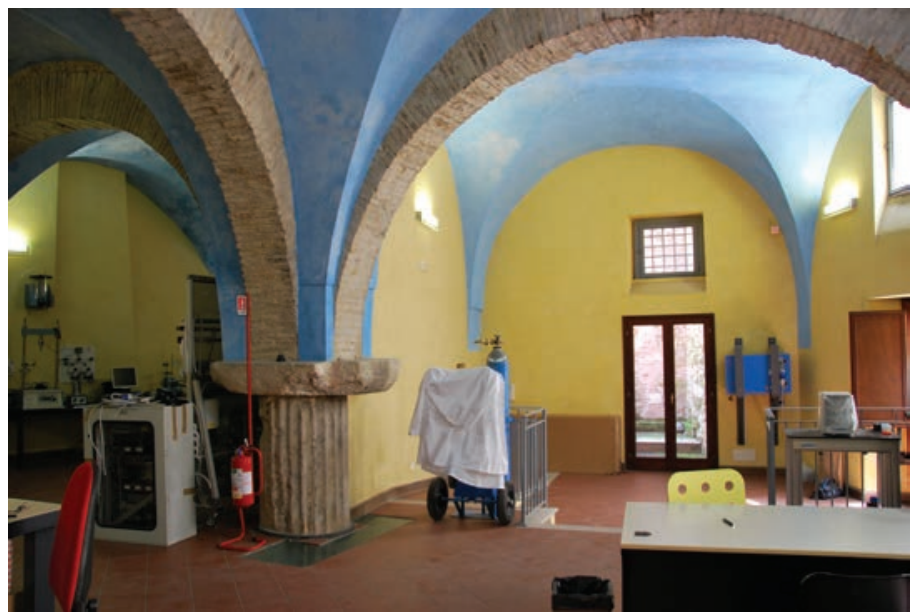

Fig. 7. Benevento, ex monastero di S. Vittorino, colonna con archi in mattoni.

\footnotetext{
${ }_{22}$ Ibidem, p. 287.

${ }^{23}$ È noto che artigiani ebrei a Benevento si dedicarono dopo il 1100 alla preparazione delle tinte o alla stessa tintura dei panni [cfr. S. BORGIA, op. cit. (n. 9 ), p. 265, 268]. Come testimonianza della loro presenza nella città di età longobarda può essere considerata la vicenda narrata da Ahimà’az ben Palțiel da Oria in una cronaca della sua famiglia scritta in prosa rimata nel 1054. Viveva alla metà del IX secolo il capostipite Amittai, intellettuale di prestigio noto come maestro e come compositore di inni sacri, esperto degli scritti tradizionali e di dottrine mistiche ed esoteriche nel cui studio aveva avuto una guida in Aharon ben Samuel ha-Nassì di Baghdād. Era questi un personaggio di straordinaria fama che intorno alla metà del IX secolo si era trasferito da Babilonia, centro del potere cabalistico, a Gaeta, a Benevento e a Oria. Non si sa perché Aharon di Baghdād visse per un certo periodo a Benevento ove fu accolto con grandi onori dalla comunità ebraica. Sta di fatto che l'episodio documenta la presenza nella città di tale comunità. Cfr. B. Klar (ed.), Meghillàt Ahimàaz; The Chronicle of Ahimàaz, with a collection of poems from Byzantine Southern Italy and additions, Jerusalem, 1944 (new ed. M. Spitzer (ed.), Jerusalem, 1974). L'importanza della cronaca per la storia del Mezzogiorno altomedievale è ben evidenziata da G. MUSCA, L'emirato di Bari, 847-871, Bari, 1964 (new ed. 1978), p. 77-9o. Su questo importante documento cfr. anche A. MILANO, Storia degli ebrei in Italia, Torino, 1963, p. 6o-62; R. BONFIL, Tra due mondi. Prospettive di ricerca sulla storia culturale degli Ebrei dell'Italia meridionale nell'alto Medioevo, in Italia Judaica, in Atti del I convegno internazionale (Bari, 18-22 maggio 1981), Roma, 1983, p. 135-158. Nel IX secolo, del resto, degli Ebrei erano in molte località del Mezzogiorno, soprattutto in Puglia, e non può sorprendere la loro presenza a Benevento ove peraltro gli affreschi di Santa Sofia attestano già nell'VIII secolo rapporti culturali fra la città longobarda e l'area siro-palestinese [cfr. N. TAMASSIA, Stranieri ed ebrei nell'Italia meridionale dall'età romana alla sveva, in N. Tamassia (ed.), Studi sulla storia giuridica dell'Italia meridionale, Bari, 1957, p. 67-162, a p. 89, 93, 101, 124-125].

${ }^{24}$ Cfr. A. ZAZO, op. cit. (n. 17), p. 63-64, n. 8, ove sono indicazioni sulle ecclesiae S. Nicolay de Grecis e S. Januarii de Grecis.

${ }_{25}$ Chronicon Sanctae Sophiae, op. cit. (n. 6), II, 5, p. 437-439, a p. 438; il cenobio, assente nella schedatura di C. LEPORE, Monasticon beneventanum, è menzionato fra i beni confermati all'abbazia di Santa Sofia dal privilegio di papa Pasquale II del 27 ottobre 1101 [Chronicon Sanctae Sophiae, op. cit. (n. 6), V, 5, p. 636-644, a p. 638], dal privilegio di Anacleto II datato 8 febbraio 1131 [Chronicon Sanctae Sophiae, op. cit. (n. 6), V, 10, p. 654-662, a p. 655] e dal privilegio di papa Callisto II del 29 novembre 1120 [Chronicon Sanctae Sophiae, op. cit. (n. 6), VI, 36, p. 778-785, a p. 78o].

${ }^{26}$ Le più antiche carte del Capitolo, op. cit. (n. 12), n. 33, p. 101-104. Secondo P.F. Kehr, W. Holtzmann (eds.), op. cit. (n. 9), p. 102, seguito da M. ROTILI, op. cit. (n. 4), p. 111, questa sarebbe la prima menzione del monastero. Sulle successive vicende cfr. S. BORGIA, op. cit. (n. 9), II, p. 144; I, p. 235;

${ }^{27}$ V. Federici (ed.), Chronicon Vulturnense del monaco Giovanni, II, Roma, 1925-38 (rist. anast. Torino, 1972 = Chronicon Vulturnense), IV, c. 154B, p. 40: «His temporibus supradicti principes (Atenolfo I e Landolfo I menzionati a c. 154A, p. 39) multa cum Sarracenis, et Grecis certamina habuerunt sed Dei misericordia victoriam acceperunt. Tunc quoque monasterium domini Salvatoris in Aliphis [...1 depredatum et incensum a Sarracenis fuerat, cuius habitatores, qui evadere potuerunt, Beneventum venerunt, et a princibus, ac civibus auxilium postulantes, Sancte Crucis in honore ecclesiam constructam acceperunt, ubi aliquandiu habitantes, Victorini martiris ecclesiam (peci)erunt, ibique cenobiolum edificantes deinceps permanserunt». V. FEDERICI, I documenti perduti o non inseriti nella Cronaca, in Chronicon Vulturnense, III, p. 123-176, a p. 148 (documento 47), fissa il saccheggio ed il conseguente trasferimento delle monache a Benevento negli anni del governo abbaziale di Godelperto (902-920), mentre il termine ad quem dev'essere contenuto entro il 910, anno
} 
un tempo imprecisato (aliquandiu), ottennero la chiesa del martire Vittorino presso la quale avrebbero edificato il loro cenobiolum, lascia intendere che la costruzione del nuovo monastero ebbe luogo verosimilmente negli anni di governo di Landolfo I e Atenolfo II, se non più tardi, e non entro il 910: infatti la fonte, a differenza di quanto infondatamente sostenuto $^{28}$, non relaziona l'attività costruttiva al periodo di Atenolfo I e Landolfo I, al quale, invece, è chiaramente collegato l'attacco dei Saraceni al San Salvatore di Alife.



Fig. 8. Benevento, ex monastero di S. Vittorino, varco sormontato da un arco a sesto acuto.



Fig. 9. Benevento, ex monastero di S. Vittorino, auditorium.
Il 26 aprile 1168 papa Alessandro III sottrasse il monastero alla dipendenza volturnense ponendolo sotto la giurisdizione della Santa Sede, riconoscendo alle monache il diritto di eleggere le badesse di cui riservò la benedizione al romano pontefice e accordando loro la facoltà di accogliere nel recin-

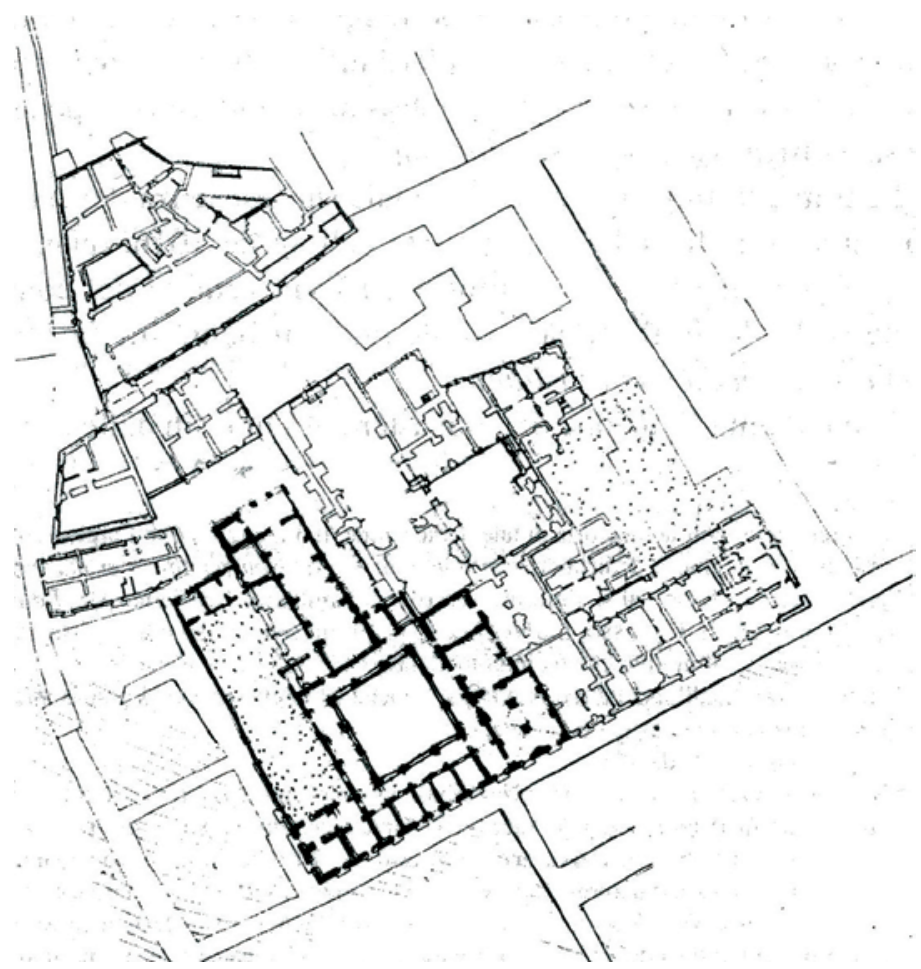

Fig. 10. Benevento, ipotesi ricostruttiva della pianta del monastero di S. Vittorino.

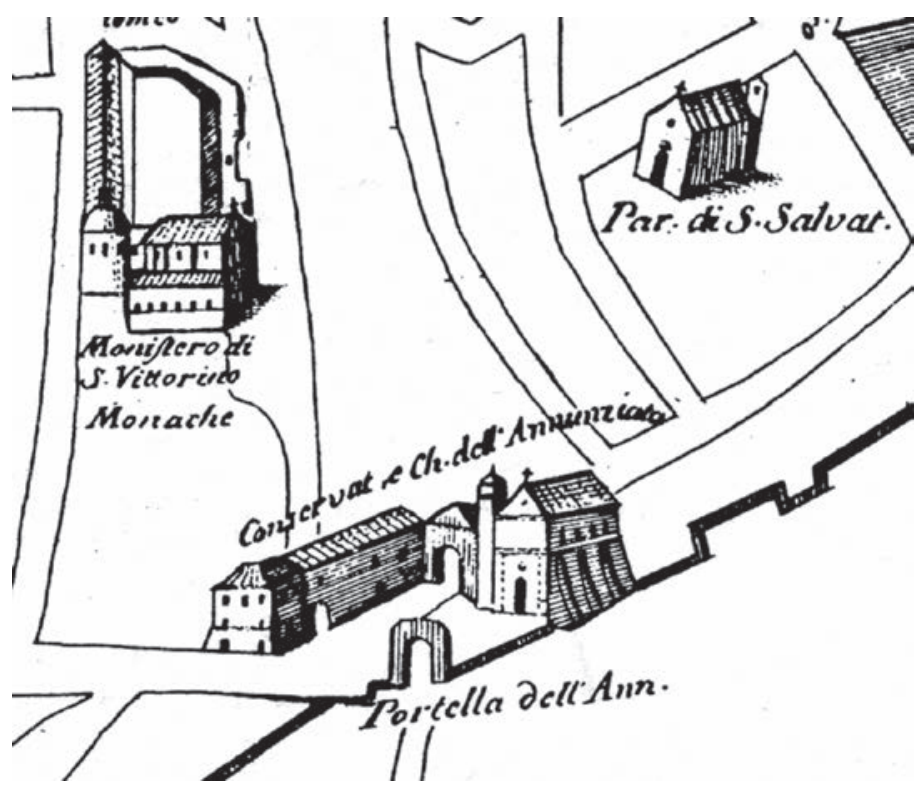

Fig. 11. Liborio Pizzella, Pianta della pontificia città di Benevento,incisa dall'Aloia, in S. Borgia, Memorie istoriche della Pontificia città di Benevento, II, 1764, fig. 1, particolare con il monastero di S. Vittorino e la chiesa del SS. Salvatore.

del decesso di Atenolfo I. Il regesto del predetto documento 47 (III, p. 148-149), desunto dal testo della cronaca e riprodotto in transunto, indica l'oblazione «della chiesa di S. Croce ai monaci di San Vincenzo al Volturno, costretti ad abbandonare la loro residenza di S. Salvatore di Alife, incendiato dai Saraceni» mentre da ERCHEMPERTI Historia Langobardorum Beneventanorum, in G. Waitz (ed.), in Monumenta Germaniae Historica (= MGH), Scriptores Rerum Langobardicarum et Italicarum saec. VI-IX, Hannoverae, 1878, p. 231-265, cap. 3, p. 236, emerge che il monastero di San Salvatore di Alife era femminile: «Pari etiam modo in territorio Alifano Deo amabili viro ecclesiam in honorem domini Salvatoris construxit, et monasterium puellarum instituit, atque dictioni sanctissimi Vincentii martiris subdidit». Federici ritiene che la concessione di S. Croce possa essere stata temporanea tanto da non aver dato luogo, probabilmente, alla redazione di un documento scritto che infatti viene proposto in transunto. E. GALASSO, L'abbazia longobarda di San Vittorino, in L'abbazia longobarda di San Vittorino in Benevento, Benevento, 1988, p. 7-19, a p. 16, segue la cronologia indicata da Federici.

${ }^{28}$ C. LEPORE, op. cit. (n. 14), p. 162. 
to conventuale i mercanti e i forestieri ${ }^{29}$. Nel 1446 papa Paolo II concesse la possibilità di affidare la consacrazione delle nuove badesse ad un vescovo scelto dalla comunità monasti$\mathrm{ca}^{30}$. Fra i numerosi possedimenti si ricordano il monastero di San Salvatore di Alife ricostituitosi alle dipendenze di San Vincenzo al Volturno alla metà del secolo X, quindi attribuito a San Vittorino nel 1168 e le chiese di San Salvatore di Prata (forse Sannitica), di Santa Croce a Porta Somma e di San Severiano nel feudo di Cancelleria, presso Benevento; nel 1308 la rendita imponibile ammontava a trentadue once, su cui gravava una decima di tre once e sei tareni ${ }^{31}$. Segnalatosi per l'esemplarità dell'osservanza della regola monastica, il cenobio vide incrementarsi il numero delle monache (solo sette nel 1542) grazie all'aggregazione della soppressa comunità cenobitica di San Diodato. Conseguenza di ciò furono i lavori di ampliamento disposti dall'arcivescovo Pompeo Arrigoni che aggregò a San Vittorino la chiesa dei Santi Simone e Giuda, poi ridotta a giardino conventuale ${ }^{32}$, e fece abbattere l'altra chiesa di San Leucio di Porta Somma, perché se ne usassero le «pietre per la frabeca»33. Nel 1628, quando erano ancora in corso i lavori di ampliamento e abbellimento della chiesa che era stata restaurata nel $1207^{34}$, il monastero ospitava ventiquattro monache professe ${ }^{35}$; nel 1737 se ne contavano trentanove ${ }^{36}$. Ricostruito dopo il terremoto del 5 giugno $1688^{37}$ venne prontamente restaurato dopo i guasti prodotti dal sisma del 14 marzo 1702. Chiuso temporaneamente nel 1799, il monastero fu soppresso nell'ottobre 1806: la chiesa e gran parte dell'edificio furono vendute nel 1809 per la somma di 3.600 ducati $3^{8}$, passando quindi, tra il 1834 e il 190o, all'Orfanotrofio dell'Annunziata ${ }^{39}$. Attualmente l'ex complesso monastico, sensibilmente trasformato, ospita un Dipartimento dell'Università degli studi del Sannio.

4. Non lontano da porta Rufina, più a occidente, sorgevano le chiese (fig. 1 n. 11) di Sant'Artellaide che risale almeno all'VIII secolo ${ }^{40}$ e di San Angelo che potrebbe essere identificata con San Angelo a Porta Nova ricordata da un diploma dei principi Pandolfo II e Landolfo V del 991 o 992 e non lontana ${ }^{41}$, a meno che non si tratti di Sant'Angelo a Porta Rufina $^{42}$. Nella zona erano inoltre l'ecclesia S. Benedicti de adobbatoris, detta più tardi de scalellis, offerta da Guaccone insieme a mulini e terreni all'abbazia di Montecassino nel

\footnotetext{
${ }^{29}$ P.F. Kehr, W. Holtzmann (eds.), op. cit. (n. 9), IX, p. 102.

${ }^{30}$ Biblioteca Capitolare di Benevento, cartella 48, n. 31.

${ }^{31}$ M. Inguanez, L. Mattei Cerasoli, P. Sella (eds.), Rationes decimarum Italiae. Campania, Città del Vaticano, 1942, n. 4662.

${ }^{32}$ Index Pacilli, op. cit. (n. 3), 354, f. 8rv: «fu profanata et diruta dall'illustrissimo signor Cardinale Arigone, fu data al monastero di Santo Vettorino per ampliare et ingrandire quello luogo, et fu unito con lo giardino, et per farlo al piano di quello delle signore monache fu ripieno di terra et oggi sta in uso di giardino».

33 Ibidem, f. 8r: «per ordine del illustrissimo signor cardinale Arigone fu diruta per pigliarne le pietre per la frabeca delle signore monache di Santo Vettorino». ${ }^{34}$ ASP-BN, Fondo S. Vittorino, IX.2. Cfr. E. GALASSO, op. cit. (n. 27), p. 13, 17.

${ }^{35}$ Index Pacilli, op. cit. (n. 3), f. 23r: «Questa chiesa è molto piccola et, per haverci unite piu monache per l'unione fatto dall'ementissimo signor cardinale Arigone come se ni è parlato a lungo piu sopre nella chiesa di Santo Deodato, hora si sta facenno la chiesa piu granne et viene bellissima. Sono 24 monache et piu et meno viveno alla regola di Santo Benedetto viveno nobilmente con le loro entrate tengono delle loro figliole alunde et sono appresso di quaranta con le serviente». A. FEOLI MASTROZZI, Memorie della S. Chiesa Beneventana, ms. sec. XIX, vol. III, Biblioteca Capitolare di Benevento 56o, f. 83v, informa che i lavori si protrassero ancora per un quindicennio tanto che la chiesa venne consacrata da Urbano Zambotti, vescovo di Montemarano, il 6 aprile 1643 . ${ }^{36}$ L. BARIONOVI, Popolazione e chiese della diocesi di Benevento nella relazione "ad limina" del 1737, in Samnium, 55, 1-2, 1982, p. $25-42$.

37 Trasferite altrove, le monache rientrarono nel ricostruito monastero solo il 10 agosto 1692 come attesta una lettera del cardinale-arcivescovo Vincenzo Maria Orsini al padre Squillante del 15 agosto riportata per stralci da A. BELLUCCI, Di una inedita ed ignota corrispondenza del cardinale Vincenzo M. Orsini, arcivescovo di Benevento, e poi papa Benedetto XIII (1680-171), in Samnium, IV, 2, 1931, p. 5-16, a p. 8-9 (il lavoro è la continuazione di contributi editi nella stessa rivista).

${ }^{38}$ Gli acquirenti furono Bartolomeo Rossi e Pasquale De Marco di Paupisi, i cui eredi nel 1829 cedettero la chiesa in enfiteusi al beneventano Pietro De Caro: cfr. A. FEOLI MASTROZZI, op. cit. (n. 35), f. 98rv.

39 Ibidem, f. 98v; E. ANNECCHINI, Breve compendio istorico delle principali notizie della città di Benevento dalla sua fondazione fino all'anno 1802 , raccolte e disposte in lezioni dialogistiche (con appendice fino al 1902 di G. Bologna), Benevento, Pubblica Biblioteca Arcivescovile "F. Pacca", ms., II, p. 92; S. DE LUCIA, Passeggiate beneventane, Benevento, 1925, ristampa anastatica, Benevento, 1983, p. 213-214.

${ }^{40}$ Cfr. LEONIS MARSICANI ET PETRI DIACONI Cronica Monasterii Casinensis, W. Wattenbach (ed.), MGH, op. cit. (n. 27), VII, 551-844, libri I, II, III (in parte); new ed. H. Hoffmann (ed.), MGH, op. cit. (n. 27), XXXIV, Hannoverae, 1980 (= LEONIS OSTIENSIS CMC), I, 18, p. 594.

${ }^{41}$ Praeceptum concessionis et confirmationis databile tra il 12 agosto 991 e il 29 novembre 992 (?), in F. Bartoloni (ed.), Le più antiche carte dell'Abbazia di S. Modesto in Benevento (secoli VIII-XIII), Regesta Chartarum Italiae, Roma, 1950, p. 11-17, a p. 14.

${ }^{42}$ C. LEPORE, op. cit. (n. 14), sostiene l'identità di Sant'Angelo a Porta Nova e di Sant'Angelo a Porta Rufina: la variante nominalistica è possibile perché la stessa chiesa può essere stata diversamente indicata [come avviene nei due documenti che il Lepore cita a conferma del suo assunto e cioè F. BARTOLONI, op cit. (n. 41), doc. n. 5 del 12 agosto 991 a p. 14 e doc. n. 17 del 28 aprile 1178 a p. 47] in relazione all'una o all'altra delle due porte dalle quali distava non molto: infatti la porta Rufina, ristrutturata nell'VIII secolo in rapporto alla realizzazione della Civitas nova promossa da Arechi II (758-787) e spostata di qualche decina di metri in avanti nel punto in cui la cinta della rinnovata area urbana si saldò a quella del IV secolo [M. ROTILI, op. cit. (n. 4), p. 91], distava poco più di $330 \mathrm{~m}$ dalla Porta Nova che è attestata lungo l'attuale via Torre della Catena. La variante nominalistica Porta Nova/Porta Rufina non può viceversa giustificarsi con la supposta identità dei due accessi alla città che erano invece distinti come risulta dal Praeceptum donationum, concessionum, confirmationum del novembre 774 [in Chronicon Sanctae Sophiae, op. cit. (n. 6), I, 1, p. 289-336, nn. 58 a p. 330,62 a p. 332 ] con il quale Arechi II fissava la quota di portatico sulla legna a favore del monastero di Santa Sofia: nel documento le porte sono elencate in senso orario iniziando con porta Aurea (arco di Traiano), per proseguire con porta Summa, porta Rufini, porta Nova, porta Sancti Laurenti (fig. 1, nn. 1, 11, 19, 24) mentre la porta Liscardi (fig. 1 n. 27), detta anche, in altre fonti, porta de Hiscardi ed equivalente alla Port'Arsa, è menzionata in una sezione successiva del complesso documento (ibidem, I, 1, p. 289-336, n. 62 a p. 332). E che la porta Nova fosse fra la quarta e la quinta torre della cinta muraria è confermato dalla corrispondenza con la via di Porta Nova e dalla presenza di un suo stipite nel tratto di mura fra due torri, una delle quali modificata nel XV secolo, allorché le difese vennero adeguate all'attacco delle artiglierie a polvere mediante l'avvolgimento dei precedenti impianti poligonali in una struttura cilindrica con base scarpata in grado di offrire spessori murari di 3-4 m e di non presentare spigoli vivi più suscettibili di danni rispetto alle superfici convesse. Nella circostanza Porta Nova venne tamponata come evidenzia la Mappa originale della città di Benevento di Luigi Mazarini (Roma, Archivio di Stato, CPG, 277 n. 1), realizzata nel 1823, prima dell'abbattimento delle mura urbiche.
} 
$797^{43}$ e la chiesa di San Renato esistente nel IX secolo ${ }^{44}$. L'ubicazione di questo edificio non lontano da Porta Rufina è attestata con chiarezza da una Charta venditionis dell'n aprile 1177 che la presenta appunto come prossima alla platea «que descendit ad portam Rufini» ${ }^{45}$.

Nella zona prossima a quella che aveva ospitato il Foro, a breve distanza dall'Arco del Sacramento (fig. 1 n. 17), fra IV e V secolo venne eretta la chiesa madre di Santa Maria (fig. 1 n. 16) rinnovata nell'VIII secolo e sensibilmente modificata in epoca romanica. Nell'area di questo edificio sorsero poi la chiesa di San Marciano nell'Episcopio documentata pochi anni dopo la fine della dominazione longobarda ${ }^{46}$ e la basilica di San Bartolomeo apostolo de Episcopio ${ }^{47}$ (fig. 1 n. 16). A breve distanza dal luogo in cui venne eretta l'ecclesia Sancti Jacobi a Foro (fig. 1 n. 21), erano il monastero di San Pietro de monachabus secondo il Borgia esistente già nell'VIII secolo ${ }^{48}$ e comunque documentato nel marzo $1047^{49}$ (fig. 1 n. 38); l'ecclesia S. Stephani de monialibus de Foro attestata nel $1101^{50}$ (fig. 1 n. 21), la quale non può essere confusa con la chiesa di Santo Stefano foris civitatem ricordata dal noto diploma di Arechi II in favore del monastero di Santa Sofia del novembre 774; ed infine la chiesa di San Festo di incerta datazione ${ }^{51}$, cui dovrebbero essere assegnati i resti della parete destra e la soglia dell'edificio in prossimità dei pontili noti come «Arco di S. Gennaro» (fig. 1 n. 43).

Vicino al Ponte di Sant'Onofrio (fig. 1 n. 22) erano le chiese di Santa Maria a Porta Gloriosa che dovrebbe risalire al VII secolo ed è comunque documentata da un atto del settembre $1092^{52}$ e quella di Sant'Angelo de Porta Gloriosa nel Cortile dei Bagni, di incerta datazione ${ }^{53}$.

5. Nell'area nord, compresa tra port'Aurea e il ponte di Sant'Onofrio, non lontano da Porta Rettore, vi erano la chiesa di San Gregorio (fig. 1 n. 13) documentata già nel $750^{54}$ e i monasteri di San Paolo «secus murum huius beneventanae civitatis» (fig. 1 n. 14) e di Sant'Adeodato (fig. 1 n13) nonché la chiesa (fig. 1 n. 12) di San Costanzo.

Sant'Adeodato/San Diodato, cenobio femminile, èattestato da un atto dell'ottobre $981^{55}$ mentre a San Paolo si riferisce probabilmente il Praeceptum donationum, concessionum, confirmationum del novembre $774^{56}$ che offre un generico riferimento topografico per la chiesa extraurbana di Santo Stefano, concessa a Santa Sofia, dicendo che era ubicata «prope $S(\mathrm{an}) \mathrm{c}(\mathrm{tu}) \mathrm{m}$ Paulum». Tuttavia la prima indicazione certa di questo cenobio maschile che sorgeva «secus murum huius Beneventane civitatis» è offerta dal diploma di Pandolfo II, Landolfo V e Pandolfo III del 18 dicembre $1012^{57}$. Compare poi in un atto del luglio $1112^{58}$ come monastero e come chiesa in documenti del 27 febbraio $1118^{59}$, del gennaio $1152^{60}$, del gennaio $1154^{61}$ singolarmente non presi in considerazione da uno studio locale ${ }^{62}$ : tutti questi documenti forniscono sostanzialmente la stessa indicazione topografica indicando un cenobio (ovvero un chiesa con relativo abate) «quod costructum est intus hanc vet(erem) Benev(entanam) civit(atem) secus trasendam puplicam que dicitur de Leone iudic(e)»; fa riferimento a San Paolo anche un documento del novembre $1110^{63}$. Svolse funzioni di parrocchia dalla fine del XII secolo al XVIII e dopo il sisma del 1688 venne ricostruita da Bartolomeo Tomaselli che l'aveva ottenuta in enfiteusi fungendo quindi da cappella privata di questa famiglia fino ai bombardamenti statunitensi del settembre 1943 .

Ricordata come parrocchia nell'Obituarium di Santo Spirito cominciato a scrivere nel $1198^{64}$ e nota perché nel 1243 fu donata dai conti Stampalupo ai Francescani che l'incorporarono nel convento costruito accanto alla loro basilica ${ }^{65}$, la chiesa di San Costanzo (fig. 1 n. 12) è pervenuta con un muro perimetrale riutilizzato come parete settentrionale del chiostro maggiore. L'affresco di un santo monaco bene-



${ }^{44}$ Catalogus regum Langobardorum, in G. Waitz (ed.), in MGH, op. cit. (n. 27), p. 496.

${ }^{45}$ ASP-BN, Fondo S. Bartolomeo, T.U., 2.

${ }^{46}$ Atto di donazione del marzo 1104 o 1105, in Le carte del capitolo, op. cit. (n. 12), n. 53, p. 163-165: Sikelgarda, figlia di Landolfo conte, moglie del fu Madelfrido conte, offre alla chiesa di S. Marciano, costruita «intus in episcopio», una vigna e un terreno in località Roseto.

${ }^{47}$ A. ZAZO, Benevento che fu: la basilica di S. Bartolomeo, in Samnium, 31, 1958, p. 226-231, a p. 226.

${ }^{48}$ S. BORGIA, op. cit. (n. 9), II, p. 191. Index Pacilli, op. cit. (n. 3), c. 11b; A. ZAZO, op. cit. (n. 17), p. 68, n. 24.

49 Le più antiche carte del Capitolo, op. cit. (n. 12), n. 38, p. 118-123, a p. 119.

${ }^{50}$ Chronicon Sanctae Sophiae, op. cit. (n. 6), V, 5, p. 636-644, a p. 638; cfr. inoltre A. ZAZO, I beni della badia di S. Sofia in Benevento nel XIV secolo, in Samnium, 29, 1956, 3, p. 131-155, a p. 166.

${ }^{51}$ A. ZAZO, op. cit. (n. 17), p. 64, n. 11.

${ }^{2}$ ASP-BN, Fondo S. Bartolomeo, Varia, II, 8.

${ }^{53}$ A. ZAZO, op. cit. (n. 17), p. 69, n. 27.

${ }^{54}$ Chronicon Sanctae Sophiae, op. cit. (n. 6), III, 19, p. 496-497, p. 496: Praeceptum confirmationis di Scauniperga e Liutprando datato marzo 751-754.

55 Ibidem, VI, 27, p. 754-756, a p. 754-755. Il Praeceptum concessionis attribuisce a Santa Sofia chiese e beni di San Vincenzo al Volturno: fra questi appunto San Adeodato/San Diodato.

${ }^{56}$ Ibidem, I, 1, p. 289-336, n. 15 a p. 301-302.

${ }^{57}$ Le più antiche carte del Capitolo, op. cit. (n. 12), n. 30, p. 89-93, a p. 89, 91.

${ }_{58}^{8}$ Ibidem, n. 55, p. 167-17o, a p. 168.

59 Ibidem, n. 56, p. 170-173, a p. 171.

${ }^{60}$ Ibidem, n. 72, p. 213-215, a p. 214.

${ }^{61}$ Ibidem, n. 74, p. 219-221, a p. 220.

${ }^{62}$ C. LEPORE, op. cit. (n. 14), p. 115-118.

${ }^{63}$ ASP-BN, Fondo S. Sofia, XXXIV, 4.

${ }^{64}$ Obituarium S. Spiritus, Biblioteca Capitolare di Benevento, ms. 28, f. 79v. Cfr. inoltre A. ZAZO, L'«Obituarium S. Spiritus» della Biblioteca Capitolare di Benevento (secc. XII-XIV), Napoli, 1963, p. 178.

${ }^{65}$ Cfr. E. ANNECCHINI, op. cit. (n. 39), II, p. 62. 


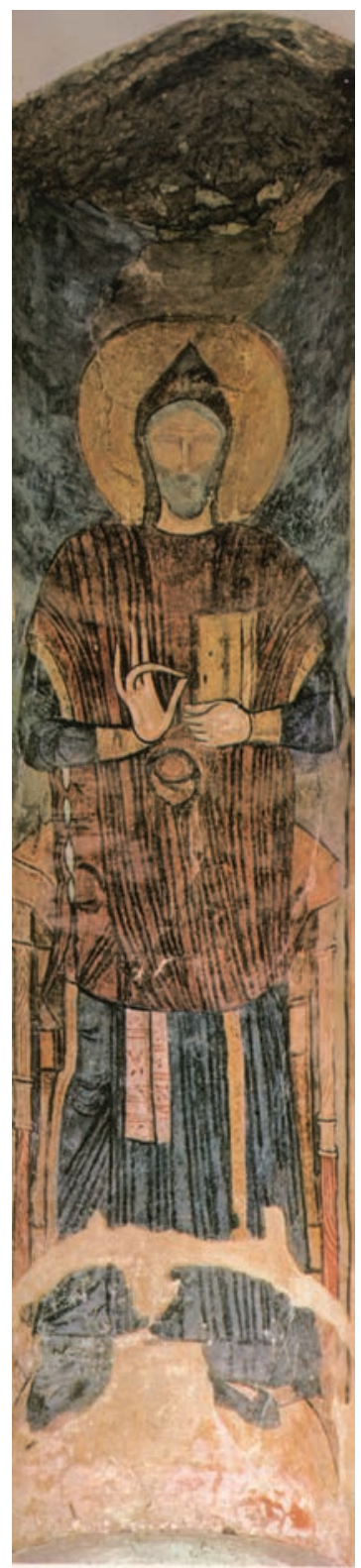

Fig. 12. Benevento, Convento di San Francesco, Santo monaco benedicente, affresco della chiesa di San Costanzo. dicente dell'XI (fig. 12) indurrebbe a porre la fabbrica nella tarda età longobarda, ma il rinvenimento di frammenti di transenne e di cornici della seconda metà del X secolo durante il restauro del complesso francescano che permise l'individuazione del muro indicato sopra $^{66}$, ha fatto pensare che essa risalga a prima del Mille.

Infine San Mauro non lontano da piazza Dogana (fig. 1 n. 12) è una chiesa documentata nel 1108 ma potrebbe risalire all'età longobarda ${ }^{67}$.

6. Nella Regio viae novae, sorgevano la chiesa e il monastero di San Giovanni a Port'Aurea (fig. 1 n. 7), attestati nel novembre 774 dalla concessionea Santa Sofia di una terra illegalmente detenuta appunto dall'abate di San Giovanni ${ }^{68}$; il 12 gennaio 936 la chiesa è menzionata dal diploma col quale Landolfo I, Atenolfo II e Atenolfo III, concedono a Odelprando sacerdote e ai suoi successori la chiesa «sacri palatji vocabulo Sancti Iohannis, que sita est intro hanc veterem Beneventanam civitatem non longe a porta Aurea» con tutte le sue pertinenze nei territori di Capua, Sant'Agata dei Goti, Tocco Caudio, Forchia, Squille (frazione di Castelcampagnano, in provincia di Caserta), Salerno e Avellino ${ }^{69}$; e ancora il 13 febbraio 967 San Giovanni è menzionata nella sua natura abbaziale, insieme a San Pietro de Duddi, nel diploma di conferma di precedenti elargizioni e di concessione delle due abbazieall'episcopato beneventano, rilasciato a Benevento dall'imperatore Ottone $\mathrm{I}^{70}$. Il 20 dicembre 950 viene indicata come «subdita nostri sacri palatii» in una concessione rilasciata all'abate Maghenolfo dai principi Landolfo II e Pandolfo $\mathrm{I}^{71}$ mentre pochi anni dopo risulta assoggettata alla giurisdizione arcivescovile alla quale sarebbe stata ulteriormente confermata da papa Leone IX il 12 luglio $1053^{72}$ e da Stefano IX il 24 gennaio $1058^{73}$. Questa posizione

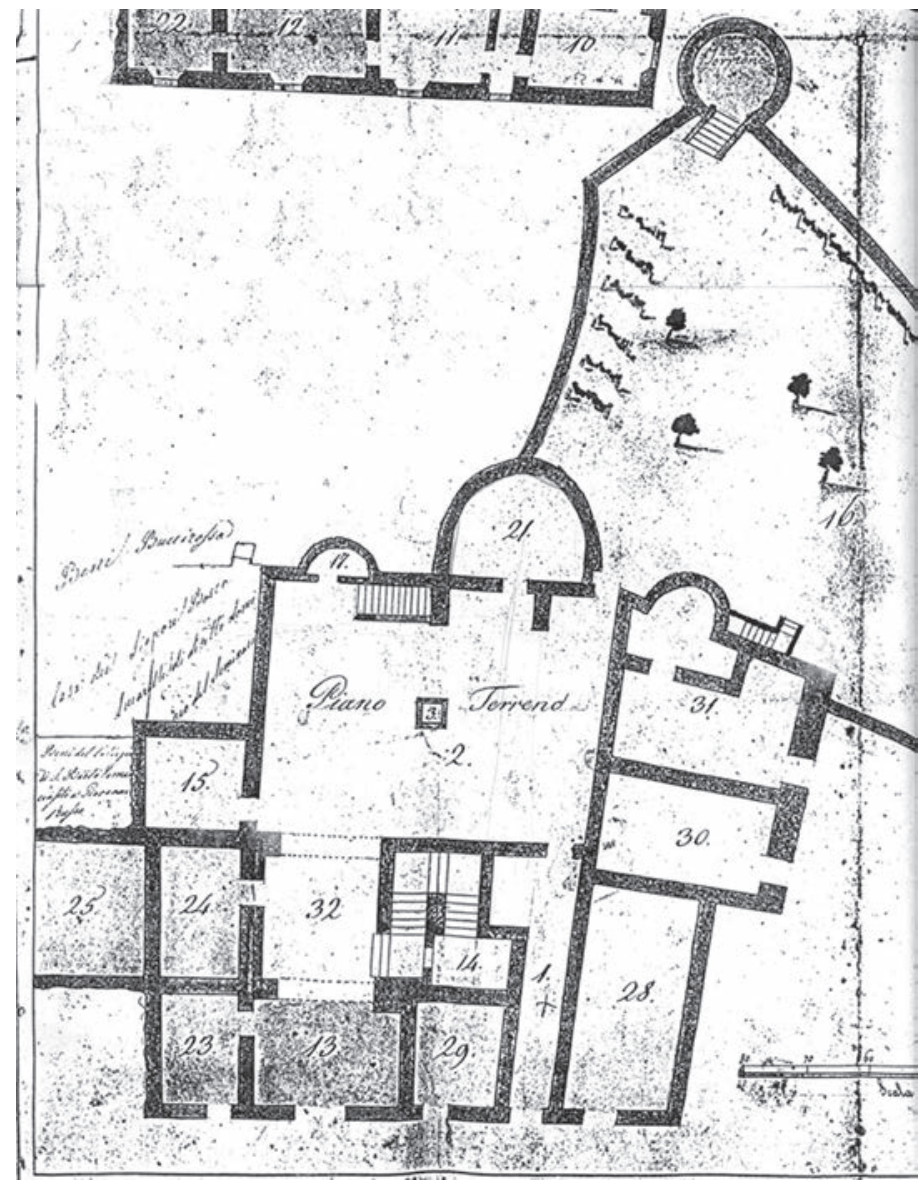

Fig. 13. Benevento, S. Giovanni a Port'Aurea, chiesa e monastero inglobati da un'abitazione, planimetria del piano terreno.

risulta confermata nei secoli XII-XIII secolo, quando è posta per lo più sotto il governo di cardinali o di delegati della Santa Sede. Svolse funzioni di parrocchia dalla fine del XII secolo e continuò ad assolvere il compito della cura d'anime anche dopo che le sue rendite erano state attribuite al Capitolo metropolitano dall'arcivescovo Arnaldo di Brusacco (1343). Nel 1581 il visitatore apostolico Pietro Lunel ne decretò la profanazione e nel 1628 era ormai diruta.

L'indicazione topografica contenuta dal titulus della chiesa si riferisce alle funzioni di porta urbica assunte dalla tarda antichità dall'arco di Traiano costruito in onore dell'imperatore di origine iberica (figg. 1 n. 8) fra il 109 e il 114 d.C. all'inizio della via Traiana realizzata appunto nel 109, ristrutturando antichi percorsi ${ }^{74}$. Ma che la chiesa sorgesse a ridosso delle mura di cinta e avesse un impianto a tre navate e tre absidi risulta dall'esame autoptico delle strutture riconoscibili all'interno dell'edificio abitativo del XVIII-XIX secolo che ne hanno trasformato l'assetto (figg. 13-14): il consistente

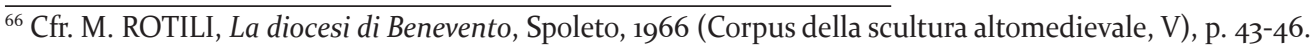

${ }^{67}$ Concessione di papa Anastasio IV del 22 settembre 1153, in Le più antiche carte del Capitolo, op. cit. (n. 12), n. 73, p. 215-219, a p. 217; P.F. Kehr, W. Holtzmann, op. cit. (n. 9), p. 67-68; atto del marzo 1164, in Le più antiche carte del Capitolo, op. cit. (n. 12), n. 84, p. 243-244, a p. 244. Cfr. inoltre Index Pacilli, op. cit. (n. 3), c. 46a; A. ZAZO, op. cit. (n. 17), p. 70, n. 30.

${ }^{68}$ Praeceptum donationum, concessionum, confirmationum, op. cit. (n. 42), p. 307.

${ }^{69}$ Le più antiche carte del Capitolo, op. cit. (n. 12), n. 8, p. 23-27.

${ }^{70}$ Ibidem, n. 16, 43-47.

${ }^{71}$ S. BORGIA, op. cit. (n. 9), I, p. 359-362.

${ }^{72}$ P.F. Kehr, W. Holtzmann (eds.), op. cit. (n. 9), p. 58.

${ }^{73}$ Ibidem, p. 58-59.

${ }^{74}$ La singolare denominazione assunta dall'arco nella sua nuova funzione di porta va collegata alla notevole qualità del monumento che celebra le imprese belliche e civili del princeps e probabilmente allo splendore dell'iscrizione posta su entrambe le sue facciate, in lettere capitali di bronzo dorato: cfr. al riguardo M. ROTILI, op. cit. (n. 4), p. 94-95. Citata con porta Summa, porta Rufini, porta Nova, porta S. Laurentii dal Praeceptum donationum, concessionum, confirmationum [op. cit. (n. 42), p. 330] del novembre 774 con il quale Arechi II fissava la quota di portatico sulla legna a favore del monastero di
} 


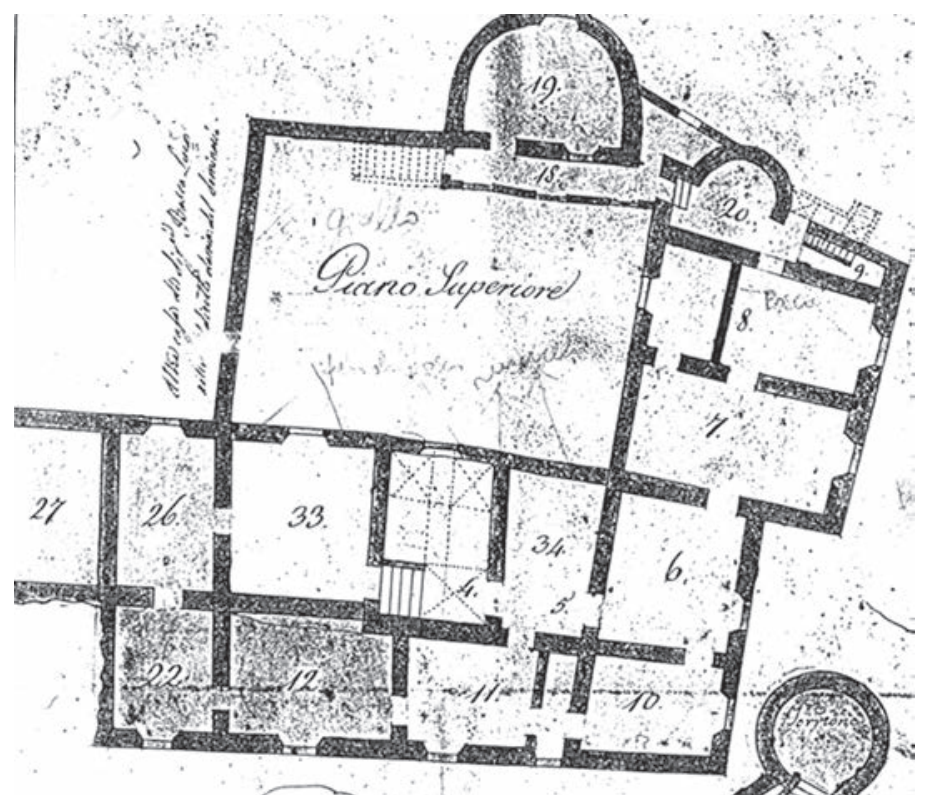

Fig. 14. Benevento, S. Giovanni a Port'Aurea, chiesa e monastero inglobati da un'abitazione, planimetria del piano superiore.

interro delle absidi e delle navate comportò la soprelevazione dell'abside centrale, realizzata probabilmente nell'ambito di una ristrutturazione dell'edificio, forse all'indomani di un grave terremoto, come, ad esempio, quello del 1125 che costrinse al restauro delle mura di IV secolo in prossimità dell'ex convento di Sant'Agostino ove una sottofondazione allora realizzata è stata individuata in uno scavo lungo via dei Rettori75 (fig. 1 n. 44) Non si può escludere che le colonne e i capitelli di riuso ancora visibili (fig. 15) siano stati riposizionati in quella circostanza.

Testimoniata dai tre atti sopra citati (il diploma dell'imperatore Ottone I del 13 febbraio 967 e le due bolle di Leone IX e Stefano IX, rispettivamente del 12 luglio 1053 e del 24 gennaio 1058), l'abbazia di San Pietro de duddi, prima ricordata, era sottoposta alla giurisdizione del metropolita. Se ne ignora l'ubicazione mentre è stato ipotizzato, peraltro senza fondamento, che possa aver costituito il nucleo originario del monastero femminile di San Pietro di dentro: in tal caso una comunità femminile si sarebbe sovrapposta ad una maschile.

7. La prossimità all'arco di Traiano-Port'Aurea connota anche altri tituli: San Matteo a Port'Aurea, chiesa documentata agli inizi del XII secolo (ma verosimilmente di età longobarda) sul lato destro dell'arco di Traiano, all'interno della cinta muraria ${ }^{76} \mathrm{e}$ in età moderna da vari atti che ne indicano l'ubicazione in un largo presso l'attuale vico Volpe, non lontano da via Giovanni De Nicastro ${ }^{77}$; la chiesa di Sant'Angelo a Port'Aurea che non è certo se corrispondesse a Sant'Angelo de Caballo. Quest'ultima denominazione ricorre anche nei tituli di San Pietro ad Caballum e di San Benedetto ad Caballum. Sant'Angelo de Caballo e San Pietro ad Cabal-

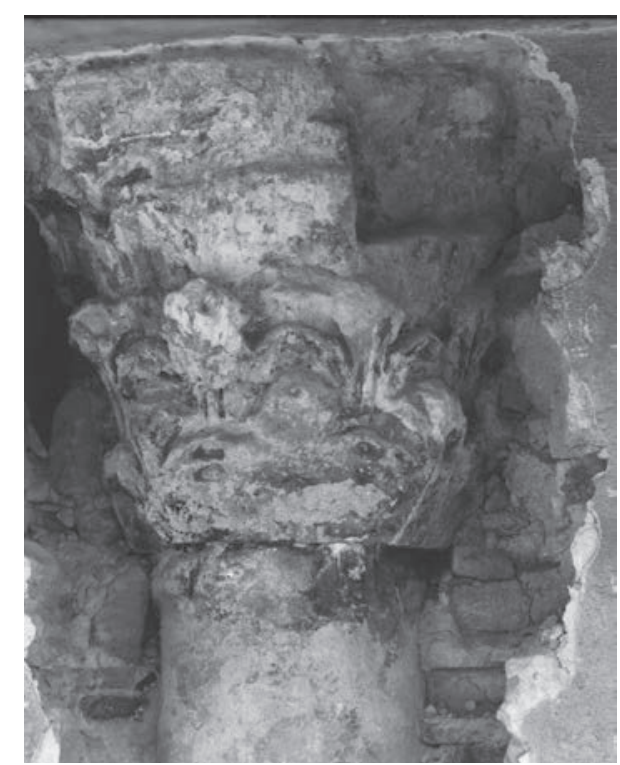

Fig. 15. Benevento, S. Giovanni a Port'Aurea, capitello.

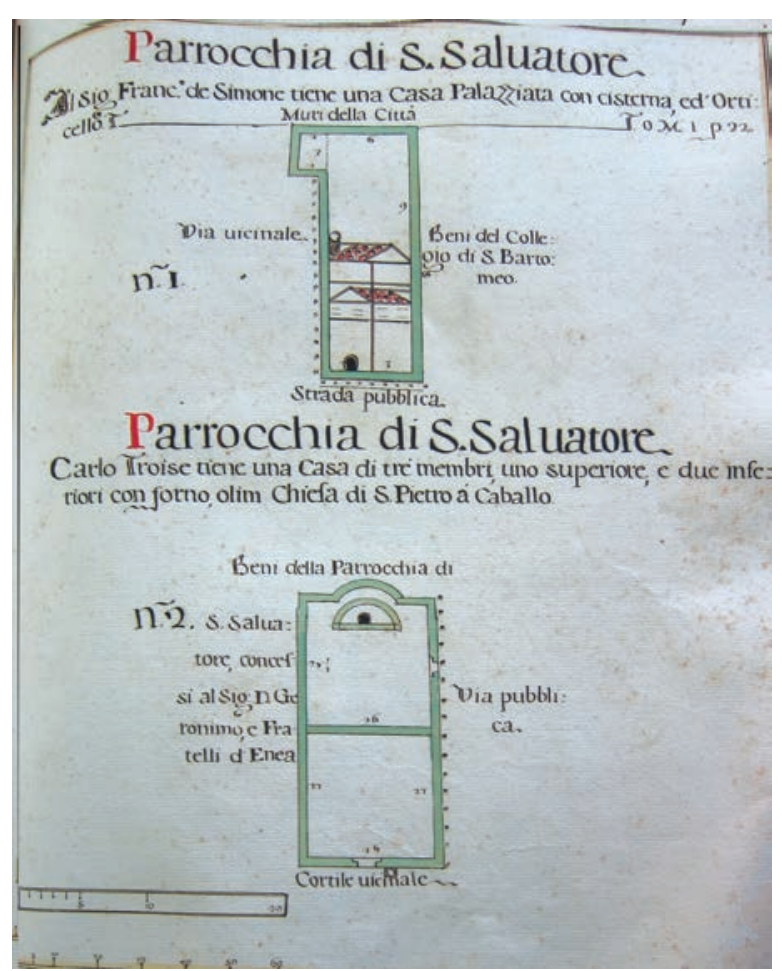

Fig.16. Chiesa di S. Pietro ad Caballum, in Platea Sofiana Orsina, A.S.P.-BN.

lum sono attestate subito dopo la fine dell'età longobarda ma si può ragionevolmente pensare che la loro fondazione sia avvenuta entro il terzo quarto dell'XI secolo ${ }^{78}$. San Pietro ad Caballum è stata riconosciuta in una casa del quartiere Trescene ${ }^{79}$ (figg. 1 n. 5 ; 16) e, nonostante la struttura simile a quella di Sant'Ilario, cioè ad aula monoabsidata con due cupole in asse, non può essere confusa con quella: infatti, se

Santa Sofia, la porta è documentata nel lungo periodo nelle sue funzioni da cartografie, da dipinti e incisioni: al riguardo cfr. M. ROTILI, op. cit. (n. 4), p. 94-95, figg. 5, 11, 30, 36, 38-41.

75 Cfr. fig. in L. TOMAY, op. cit. (n. 13), p. 119-151, a p. 122 fig. 4.

${ }^{76}$ Atto di aprile 1104, ASP-BN, Fondo S. Sofia, XXXVI, 5.

77 Ricordo quelli del 15 gennaio 1723 per notar Mattia de Agostino e del 9 giugno 1726 per notar Bartolomeo Leone, in Instrumenta varia, Benevento, Parrocchia del SS. Salvatore, Archivio, ms, ff. 131r-132v; inoltre l'Index Pacilli, op. cit. (n. 3), c. 18b riporta: «S. Matteo de Porta Aurea [...] che sta sopra e rimpetto detta Porta Aurea mediante via pubblica». Cfr. inoltre M. ROTILI, op. cit. (n. 4), p. 113,227 nota 143.

${ }^{78}$ Per San Pietro ad Caballum cfr. atti del novembre 1108 e del febbraio 1132, ASP-BN, Fondo S. Sofia, XII, 36; IV, 1; Repertorium S.S., op. cit. (n. 3), cc. 57a, 40. Cfr. inoltre A. ZAZO, op. cit. (n. 50), p. 131-166, a p. 166; Repertorium S.S., op. cit. (n. 3), c. 30 .

${ }_{79}$ M. ROTILI, op. cit. (n. 4), p. 110-111. 
da una parte l'Index Pacilli del 1628 riferisce che «In contrada Port'Aurea a sinistra, uscendo, il Capitolo tra gli altri territori ha un orto che confina colla chiesa di Sant'Ilario, prima chiesa che si trovi a mano manca» ${ }^{80}$, dall'altra documenta che San Pietro ad Caballum era invece «sopra S. Agostino et tra le infrascritte chiese: San Matteo de Porta Aurea [...], S. Benedetto ad Caballum, chiesa parrocchiale profanata che sta posta dietro all'orto di S. Sofia et davanti confina con la via pubblica» ${ }^{8}$; inoltre la più tarda Memoria storica delle chiese di Benevento, posteriore all'Index Pacilli, di San Pietro dice: «Stava sopra S. Agostino, è propriamente la casa concessa a Nicola Troisi della Badia di S. Sofia ${ }^{82}$. Queste testimonianze risolvono i dubbi sull'identità dell'edificio sollevati da una pianta della Platea Sofiana Orsina ${ }^{83}$ confermando del resto quanto riferisce il più antico documento relativo a Sant'Ilario nel quale è detto che il monastero era costruito «a foris prope portam Auream» ${ }^{84}$.

Le tre chiese de Caballo o ad Caballum traggono il nome dall'area retrostante il monastero di Santa Sofia menzionata da una Cartula concessionis rilasciata il 25 agosto 1082 dal rettore Stefano Sculdascio, con il consenso del collega Dacomario $^{85}$, all'abate di Santa Sofia Madelmo: durante i lavori di pavimentazione di piazza Piano di Corte, vicina al cosidetto «loco Caballo» ma non coincidente, furono rinvenuti (evidentemente non in posto) i frammenti di un cavallo marmoreo che vennero affidati al Museo del Sannio ${ }^{86}$ e che sembrerebbero testimoniare la presenza di una statua equestre nei pressi del Sacrum palatium.

San Benedetto ad Caballum si identifica con la chiesa di San Benedetto ad Xenodochium documentata nel settembre 742 da un Praeceptum confirmationis del duca Gisulfo $\mathrm{II}^{87}$ e poi varie volte ricordata: per esempio dal Praeceptum donationum, concessionum, confirmationum di Arechi II (novembre 774$)^{88}$, dallo Iudicatum definitionis dello stesso Arechi II dell'agosto 762 inerente la curtis di Montella ${ }^{89}$ e dal privilegio di papa Pasquale II del 27 ottobre $110^{90}$. La coincidenza delle due chiese è provata dal diploma di Pandolfo III e Landolfo VI del luglio 1050, che autorizza la costruzione, presso la chiesa di San Michele Arcangelo «que constructa esse videtur foras hanc cibitate(m) ultra porta(m) Aurea(m), trans ipso ponticello frabito ${ }^{91}$, di un nuovo xenodochio in sostituzione di quello vecchio ormai in rovina annesso alla chiesa di San Benedetto «in loco ubi ad Caballo dicitur». Poco dopo la metà dell'VIII secolo, sotto il governo dell'abate Maurizio, il cenobio risulta dotato di terre, case e condome a Benevento e in Irpinia. La sua autonomia venne meno poco dopo perché Arechi II lo assoggettò a Santa Sofia stabilendovi la residenza dei prepositi del nuovo monastero e disponendo che questi continuassero ad occuparsi dell'accoglienza dei pellegrini con la decima parte delle rendite sofiane ${ }^{92}$. Gli abati sofiani avrebbero garantito al cenobio prosperità per un certo tempo tanto che alla fine del IX secolo era ancora attivo; ma le sue fortune declinarono rapidamente se nel luglio 1050, come indica il Praeceptum sopra menzionato di Pandolfo III e Landolfo VI, si rese necessario decretare la costruzione di un nuovo ospizio presso la chiesa di Sant'Angelo a Ponticello: nel corso del XII secolo questa è ancora menzionata come dipendenza sofiana93 mentre risulta svolgere funzioni di parrocchia sul finire del secolo ${ }^{94}$. E come tale risulta nuovamente attestata nei decreti della visita apostolica del 1581; ma già allora era così mal tenuta, che ne fu decretata la demolizione o la profanazione. Già completamente diruta nel $1628^{95}$, fu comprata di lì a pochi anni dai marchesi De Simone che prima del 1641 la fecero demolire per creare davanti al loro palazzo uno spazio corrispondente a quella che sarebbe stata la piazza Venanzio Vari ora inglobata nell'ampliata piazza Arechi II ${ }^{96}$.

8. San'Ilario a port'Aurea la cui struttura a due cupole in asse ne comporta la datazione alla fine del VII-inizi dell'VIII secolo è un'aula absidata divisa in due campate leggermente disuguali perché quella contigua alla parete di fondo misura m 6,80 x 6,80 mentre l'altra è un po' più corta (fig. 1 n. 6; 17). Ciascuno di questi elementi è delimitato da tre archi

${ }^{80}$ Index Pacilli, op. cit. (n. 3), c. 43 b.

${ }^{81}$ Ibidem, c. $18 \mathrm{~b}$.

${ }^{82}$ Memoria storica delle chiese di Benevento, ASP-BN (n. 3), ms.

${ }_{3}^{3}$ Platea Sofiana Orsina, ASP-BN (n. 3), ms. f. 7, n. 2.

${ }^{84}$ S. BORGIA, op. cit. (n. 9), III, p. 136-138; P.F. Kehr, W. Holtzmann (eds.), op. cit. (n. 9), IX, p. 41 n. 101,77 n. 1.

${ }_{5}$ Chronicon Sanctae. Sophiae, op. cit. (n. 6), VI, 24, p. 744-747, a p. 745-746.

${ }^{86}$ Sulla sistemazione dell' «area caballi, in qua statua equestris exurgebat» e sul rinvenimento e la destinazione dei frammenti al locale museo cfr. A. IAMALIO, Il leone del Castello di Benevento, in A. IAMALIO, Saggi di storia beneventana, Napoli, 1940, p. 165-173, a p. 171-172.

${ }_{87}$ Chronicon Sanctae Sophiae, op. cit. (n. 6), I, 23, p. 371-373, a p. 372.

${ }^{88}$ Praeceptum donationum, concessionum, confirmationum, op. cit. (n. 42), p. 291-292.

${ }^{89}$ Chronicon Sanctae Sophiae, op. cit. (n. 6), II, 15, p. 460-464, p. 461.

${ }^{90}$ Ibidem, V, 5, p. 636-644, a p. 638; cfr. inoltre A. ZAZO, op. cit. (n. 50), p. 166.

${ }^{91}$ Ibidem, III, 50, p. 580-585, a p. 580-582.

${ }_{92}$ Praeceptum donationum, concessionum, confirmationum, op. cit. (n. 42), n. 1 p. 291-292: «in primis eccl(esi)a(m) S(an)c(t)i Benedicti loco qui vocatur Xenodochium, quod positum est iuxta ipsum monasterium cum om(n)ibus suis p(er)tinentibus, hoc et statuimus ut prepositus iam dicti S(an)c(t)e Sophie monasterii ibi sedeat ibiq(ue) sit porta ad hospites suscipiendos, pro quo et addimus ut decima o(mn)ium frugum ibi annualiter ex monasterio detur ad stipendium peregrinor(um), et sicut ab antiq(ui)s rectoribus predicti S(an)c(t)i Benedicti eccl(esi)a possessa fuit amodo et deinceps S(an)c(t)e Sophie monasterio potestati subiaceat».

93 La conferma è nel privilegio di papa Pasquale II del 27 ottobre 1101 [Chronicon Sanctae Sophiae, cit. (n. 6), V, 5, p. 636-644, a p. 638], nel privilegio di Anacleto II datato 8 febbraio 1131 (ibidem, V, 10, p. 654-662, a p. 656) e nel privilegio di papa Callisto II del 29 novembre 1120 (ibidem, VI, 36, p. 778-785, a p. 780); cfr. inoltre ASP-BN, Fondo S. Sofia, VIII, 10 (anno 1185).

${ }_{94}$ Cfr. A. ZAZO, L’Obituarium Sancti Spiritus della Biblioteca Capitolare di Benevento (secc. XII-XIV), Napoli, 1963, p. 191-192; M. ROTILI, op. cit. (n. 4), p. 92, 110.

95 Index Pacilli, op. cit. (n. 3), f. I 8v: «Sta in forma di chiesa ma diruta».

${ }^{96}$ Cfr. A. ZAZO, op. cit. (n. 50), p. 166 nota 33. 


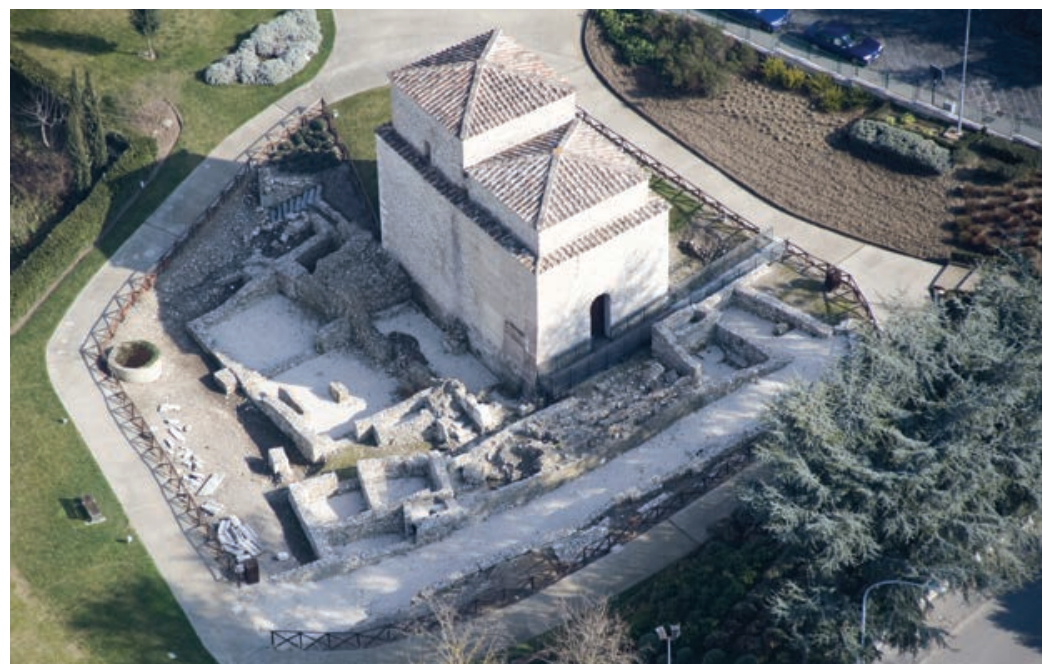

Fig. 17. Benevento, S. Ilario a port'Aurea.

poggianti su piedritti innestati nei muri perimetrali e da un quarto arco, di dimensioni doppie degli altri, che è in comune fra i due corpi di fabbrica nel punto di contiguità. Come sovente avviene nelle chiese a cupole in asse o con una unica cupola centrale inserita in una copertura voltata a botte, l'esistenza di piedritti aggettanti rispetto alle pareti d'ambito determina la formazione, in ciascuna campata, di una croce greca fortemente contratta. Al di sopra degli archi, agli angoli, sono quattro pennacchi a cuffia sui quali grava il peso delle due cupole di diversa altezza. Si tratta di elementi atti a consentire il passaggio dalla forma quadrata della campata a quella circolare della cupola (figg. 18-20). La copertura all'esterno è formata da due tiburi separati e con tetto a padiglione che s'innestano sul parallelepipedo inferiore coronato da uno spiovente rivestito di tegole ricurve. Il tiburio della campata prossima all'abside è il più alto e reca

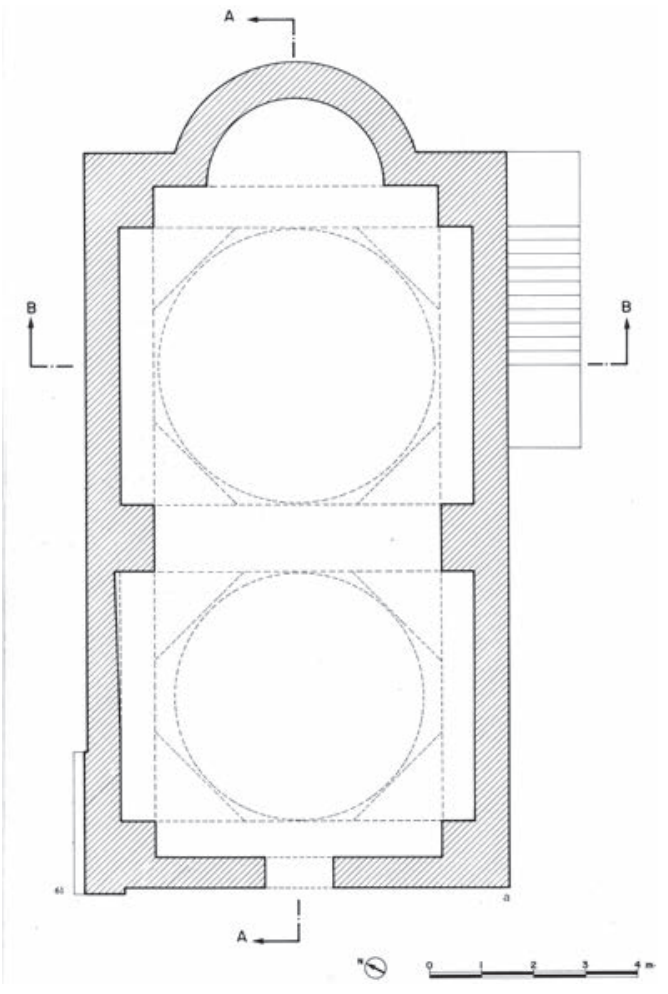

Fig. 18. Benevento, S. Ilario a port'Aurea, pianta. una monofora al centro di ognuno dei tre lati liberi. La porta d'ingresso è stretta e alta e termina con un arco in tufi e mattoni. La stessa tecnica si riscontra nei vigorosi archi che articolano lo spazio interno e nelle monofore del tiburio più alto. Fa eccezione la ghiera dell'abside, realizzata in laterizi come i piedritti che la sostengono. Per il resto la muratura è ad opus incertum salvo l'impiego di materiali di risulta sia con funzione decorativa, sia come rinforzi negli angoli (figg. 21-23). Parti di fregi sono sulla parete orientale all'esterno ma anche all'interno, ove in basso, poco dopo l'ingresso, è stato messo in luce un frammento di fregio ionico del tipo ben documentato in città. La tecnica muraria è sembrata meno evoluta dell'opus mixtum con cui è costruita Santa Sofia. Questo elemento, peraltro non determinante, ma soprattutto la copertura a cupole in asse e la sostanziale affinità con il tempietto di Seppannibale (fig. 40) presso Fasano (provincia di Brindisi), anch'esso con due cupole sulla navata centrale (mentre le navate laterali sono coperte da volte a semibotte) e con un ciclo pittorico dipendente da quello di Santa Sofia, hanno orientato la datazione alla fine del VII-inizi dell'VIII secolo, in contrasto con quanto proposto dal Venditti che ha assegnato l'edificio all'XI secolo in base al riscontro con la chiesa pugliese di San Rocco a Turi ${ }^{77}$.

L'edificio beneventano, testimoniato per la prima volta nel novembre 1110 da una carta relativa ad un orto di proprietà dell'ecclesia vocabulo Sancti Ylari $9^{8}$, è documentato come sede monastica solo nel dicembre 1148, quando Pietro cardinale diacono di Santa Maria in via Lata nonché rettore pontificio di Benevento, concesse in censo perventinove anni una casa di proprietà della curia a «Gaydo filio quondam Petri, qui sum procurator et vicecomes monasterii Sancti Ylari quod constructum est a foris prope Portam Auream» ${ }^{99}$.

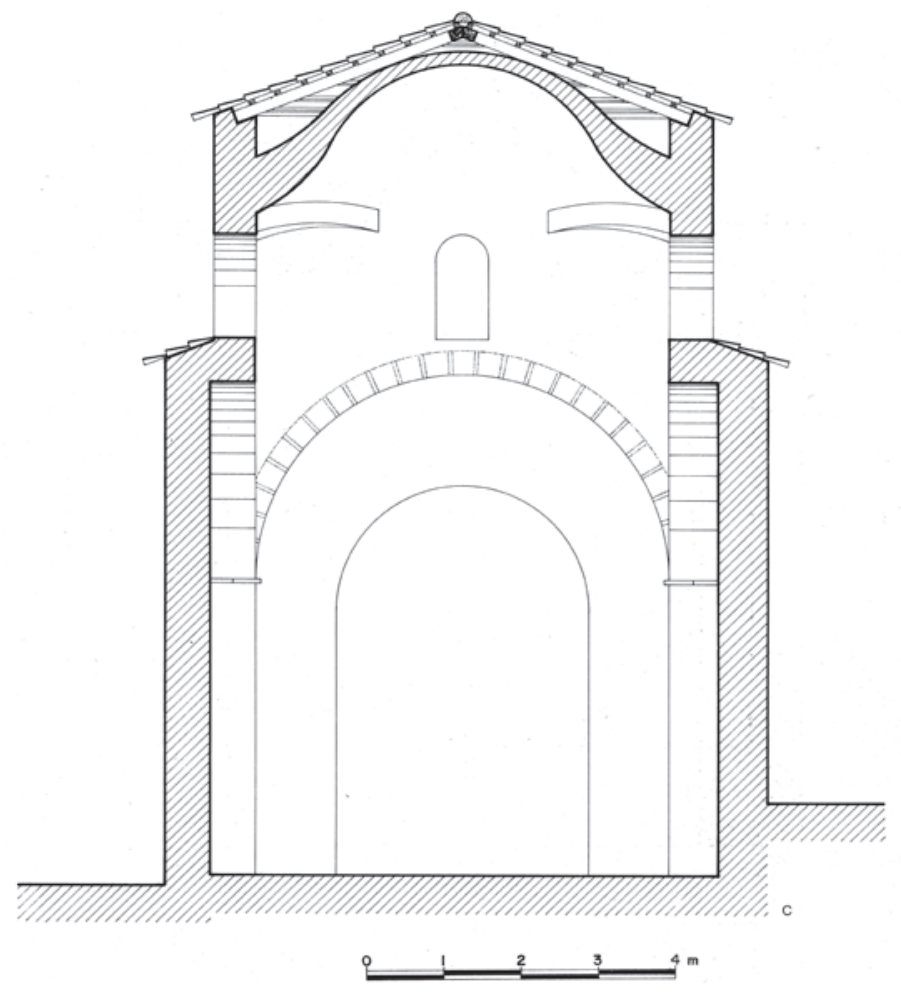

Fig. 19. Benevento, S. Ilario a port'Aurea, sezione B-B.

${ }^{97}$ A. VENDITTI, Architettura bizantina nell'Italia meridionale, Campania, Calabria, Lucania, Napoli, 1967, p. 588.

${ }^{98}$ ASP-BN, Fondo S. Sofia, XXXIV, 4.

${ }_{99}$ S. BORGIA, op. cit. (n. 9), III, p. 136-138; P.F. Kehr, W. Holtzmann (eds.), op. cit. (n. 9), IX, p. 41, n. 101, 77, n. 1. 


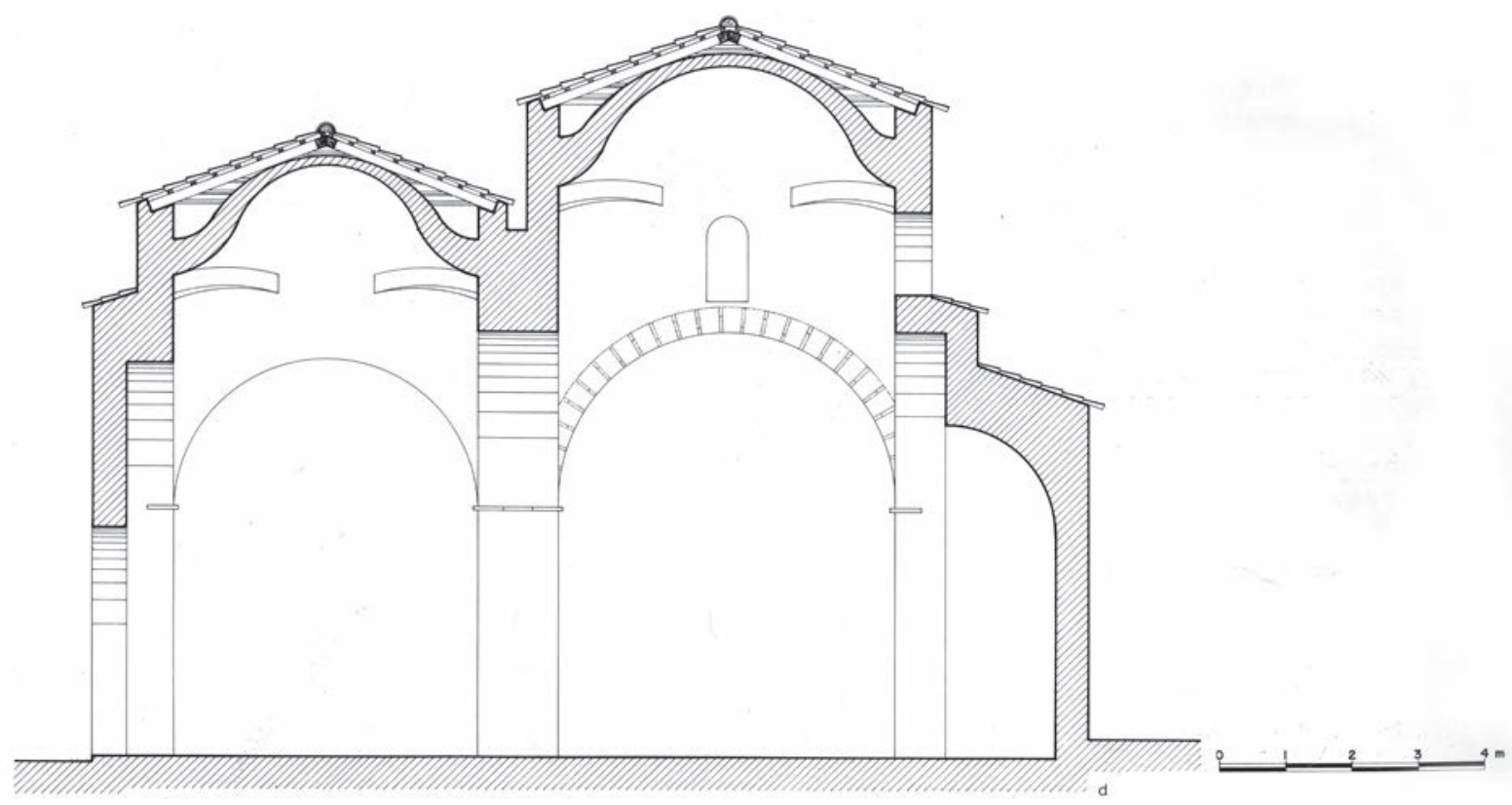

Fig. 20. Benevento, S. Ilario a port'Aurea, sezione A-A.

Indicata come chiesa parrocchiale alla fine del XII secolo, risulta poco dopo dipendente dal monastero femminile di San Paolo extra moenia di Avellino e nella prima metà del secolo XV è ormai semiabbandonata tanto che il $1^{\circ}$ gennaio 1443 papa Eugenio IV attribuì una parte delle sue rendite (per l'importo di dieci ducati) alla mensa del Capito metropolitano al quale l'avrebbe unita definitivamente papa Giulio II nel $1504^{100}$. Tuttavia la dipendenza da San Paolo ebbe termine solo nel 1479 quando papa Sisto IV conferì il beneficio relativo alla chiesa (una rendita annua di quaranta fiorini d'oro) al chierico beneventano e maestro di grammatica Pietro Bartolazio $^{101}$. Trasformata in casa colonica agli inizi del Settecento, la chiesa era quasi irriconoscibile negli anni venti del Novecento quando il Bertarelli la individuò ${ }^{102}$; ma si dovette attendere il 1956 per avere il primo studio del monumento ${ }^{103}$ cui ne sono seguiti altri nella seconda metà degli anni Sessanta e all'inizio e alla fine degli anni Settanta ${ }^{104}$ che portarono a modificare la datazione della chiesa, inizialmente fissata tra la fine del VI e i primi del VII secolo ${ }^{105}$.

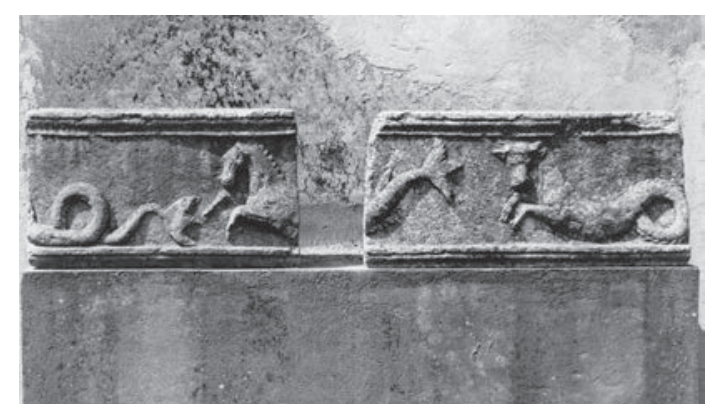

Fig. 21. Benevento, Museo del Sannio, frammento di fregio ionico.



Fig. 22. Benevento, S. Ilario a port'Aurea, frammento di fregio ionico.
Recenti scavi archeologici, seguiti da lavori di restauro, hanno evidenziato che l'edificio sorge su muri di terrazzamento in opus coementicium entro cortine di laterizi di fine I-inizi II secolo e inoltre hanno parzialmente riportato in vista le strutture del monastero.

\footnotetext{
${ }^{100}$ S. BORGIA, op. cit. (n. 9), III, p. 137.

${ }^{101}$ Biblioteca Capitolare di Benevento, cartella 42, n. 3: «ecclesia Sancti Ilarii grangia extra muros [...] quam quondam Iohannes de Barberiis monachus ordinis s. Benedicti illius rector dum viveret obtinebat [...] sine cura est et grangia monasterii monialium S. Pauli Avelini existit [...] cuius fructus quadraginta florenorum auri de camera».

${ }^{102}$ L.V. BERTARELLI, Guida d'Italia del Touring Club Italiano. L'Italia meridionale, III. Campania, Basilicata e Calabria, Milano, 1928 , p. 334.

${ }^{103}$ Cfr. M. ROTILI, La chiesa di S. Ilario a Port'Aurea a Benevento, Atti del $3^{\circ}$ Congresso internazionale di studi sull'Alto Medioevo (Benevento, Montevergine, Salerno, Amalfi, 14-18 ottobre 1956), Spoleto, 1959, p. 525-531.

${ }^{104}$ Cfr. ad esempio M. ROTILI, La cultura artistica nella Longobardia minore, Atti del Convegno sul tema "La cultura in Italia fra Tardo Antico e Alto Medioevo" (Roma, C.N.R., 12-16 novembre 1979), Roma, 1981, p. 837-866, a p. 864.

${ }^{105}$ M. ROTILI, op. cit. (n. 103), p. 530; ID., Architettura e scultura dell'Alto Medioevo a Benevento, in XIV Corso di cultura sull'arte ravennate e bizantina, Ravenna, 1967, p. 293-307, a p. 300.
} 
9. Ad Arechi II si devono la fondazione di Santa Sofia e del monastero benedettino femminile da lui annesso nel 774 (fig. 24) (106 $^{10}$ he contribuirono a incrementare il panorama dell'edilizia religiosa della città, già fitto di chiese e monasteri progressivamente istituiti nel corso dell'alto medioevo ${ }^{107}$. Nel X secolo il monastero divenne maschile e nel XII, sotto l'abate Giovanni IV, fu oggetto di un significativo intervento edilizio consistente soprattutto nella ricostruzione del chioStro (PERPETUIS ANNIS STAT FAMA QUARTI IOHANNIS/ PER QUEM PASTOREM DOMUS HUNC HABET ISTA DECOREM, recita il distico iscritto su un capitello): una iniziativa da rapportare, come la produzione libraria e artistica derivante dalla competenza dei monaci e dalla disponibilità del materiale scrittorio, al significativo potenziale immobiliare e fondiario del monastero.

La fondazione di Santa Sofia nel 758 rientra nel disegno della coesione politico-sociale perseguito da Arechi II, quindicesimo duca longobardo di Benevento ${ }^{108}$. È possibile che l'iniziale dedicazione alla stessa santa alla quale era intitolato il monastero di Santa Sofia a Ponticello, fondato dall'abate Zaccaria entro i primi tre decenni dell'VIII secolo ${ }^{109}$ poco fuori Benevento, lungo la via Traiana, fosse stata funzionale alle esigenze politiche del giovane duca, di probabili origini friulane, quindi estraneo all'ambiente beneventano al quale era stato imposto dal re Desiderio per porre riparo allo sfaldamento della coesione politica del ducato meridionale dopo un ventennio di rivolte di palazzo, sollevazioni popolari, governi labili e imposizioni di duchi da parte dei sovrani pavesi: il ventitreenne Arechi, ebbe verosimilmente l'esigenza di raccordarsi alla società longobarda di Benevento e non sorprende che l'abbia fatto attraverso la creazione di un polo religioso della sua gens strutturato inizialmente su una devozione locale.

Solo dopo la sconfitta del suocero da parte di Carlo, re dei Franchi, nel 774, Arechi avrebbe ravvisato l'esigenza di sostanziare in maniera diversa la fondazione della chiesa e ciò avrebbe fatto manifestando l'intenzione devozionale di ottenere la propria redenzione in quanto fondatore nonché la salvezza della sua gens e della patria, cioè dell'organismo sociale e territoriale posto sotto il dominio del capo politico, attraverso la dedicazione dell'edificio alla divina sapienza di

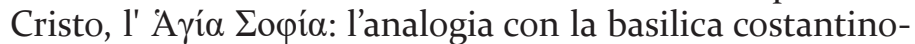
politana rifondata da Giustiniano, evidenziata alla fine del IX secolo da Erchemperto ${ }^{110}$, risulta evidente. Santa Sofia divenne così il sacrario della gens Langobardorum da tempo convertita, perché in essa vennero custodite le reliquie di San Mercurio e dei XII Fratelli Martiri ${ }^{111}$. L'attesa di favori divini richiesti dal sovrano per la sua gente è indicata dalle formule impiegate da Arechi II in due Praecepta oblationis e in un Praeceptum concessionis del novembre 774 (Benevento, in palatio) a favore della chiesa «quam a fundam(en)tis edificavi

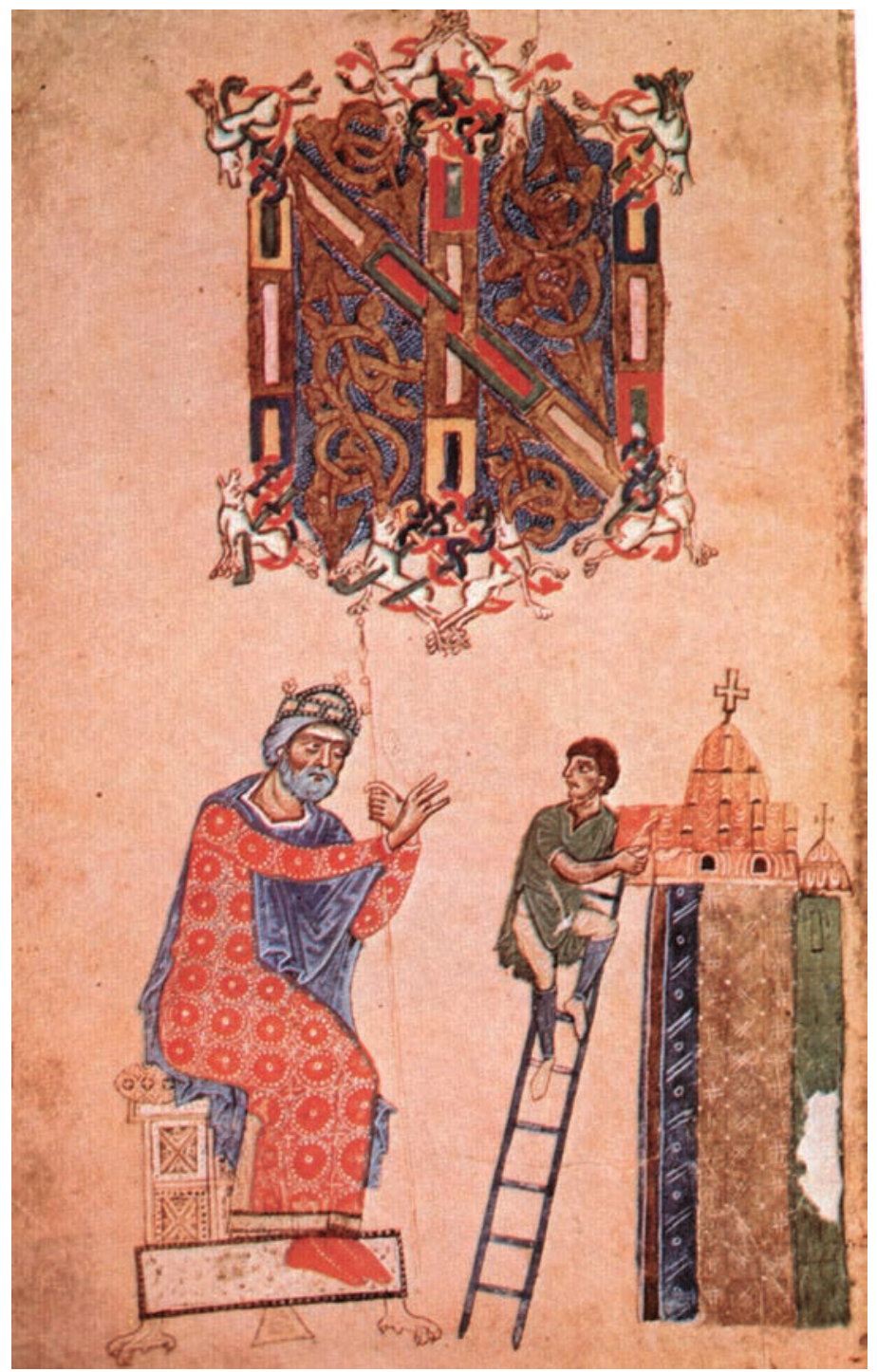

Fig. 24. Arechi II presiede alla costruzione della chiesa di S. Sofia. Città del Vaticano, Biblioteca Apostolica Vaticana, ms. Vat. Lat.4939, Chronicon Sanctae Sophiae, f. $28 r$.

$\mathrm{p}$ (ro) redemptione anime mee seu $\mathrm{p}$ (ro) salvatione gentis nostre et patrie ${ }^{112}$; risulta inoltre, sia pure in termini meno ampi, dalle parole di Leone Ostiense, il quale parla della destinazione dell'edificio «ad tutelam et honorem patriae» con riferimento alla salvezza del territorio, della sovranità e dell'identità nazionale e morale del corpo politico ${ }^{113}$; e ancora è espressa dagli Acta transalationis $S$. Mercurii martyris nel punto in cui è detto che il santo venne tumulato in Santa Sofia «ad tutelam urbis», ovvero in qualità di «dominii eiusdem loci tutor et urbis» ${ }^{114}$. Le varie formule adoperate nel 774, nel rivelare lo stretto legame tra sovrano e sudditi, i quali beneficiano dei meriti che il primo si è guadagnati di fronte

\footnotetext{
${ }^{106}$ M. ROTILI, op. cit. (n. 4), p. 189; Praeceptum donationum, concessionum, confirmationum, op. cit. (n. 42), a p. 290.

${ }^{107}$ M. ROTILI, op. cit. (n. 4), p. 110-124, 154-155.

${ }^{108}$ Ibidem, p. 185-187.

${ }^{109}$ M. ROTILI, op. cit. (n. 4), 115.

no ERCHEMPERTI Historia Langobardorum Beneventanorum, op. cit. (n. 27), III, p. 236.

${ }^{\text {mI }}$ M. ROTILI, op. cit. (n. 4), p. 107-109, 143-155, 184-201.

${ }^{122}$ Praecepta oblationis, novembre 774, Benevento, in palatio, in Chronicon Sanctae Sophiae, op. cit. (n. 6), I, 1, p. 279-280, 281-282; Praeceptum concessionis, novembre 774, Benevento, in palatio, in Chronicon Sanctae Sophiae, op. cit. (n. 6), I, 1, p. 283-284.

${ }^{\text {"3 }}$ LEONIS OSTIENSIS CMC, op. cit. (n. 4o), I, 9, p. 586.

${ }^{114}$ Translatio Sancti Mercurii, G. Waitz (ed.), in MGH, op. cit. (n. 27), Sanctorum Translationes Beneventi factae, p. 576-580, a p. 578; M. ROTILI, op. cit. (n. 4), p. 107-109, 143-155, 184-201.
} 



Fig. 25.a-b, Benevento, S. Sofia.

a Dio con l'esercizio della regale pietà, contribuiscono a specificare la natura religiosa e politica assunta da Santa Sofia nel 774 e quella dell'iniziativa di Arechi. Come nel modello costantinopolitano della basilica giustinianea, cui l'edificio beneventano si richiama con l'intitolazione ma non per le caratteristiche architettoniche, risalta dunque la funzione pubblica e nazionale della chiesa, la quale non poté essere la cappella palatina, identificata nel San Salvatore in palatio.

La chiesa (figg. 1 n. 4; 25-26), ove il principe si recava abitualmente a pregare, presenta tre absidi nel muro ad andamento circolare che assume forma spezzata oltre la zona presbiteriale per concludersi negli elementi residuali dell'originaria facciata a profilo convesso (che era lunga solo $9 \mathrm{~m}$ ) incorporati dal prospetto barocco edificato dopo il sisma del 5 giugno $1688^{15}$. Lo spazio interno (figg. 27-29) è scandito da colonne e pilastri disposti a formare un esagono centrale e un concentrico decagono fra i quali si svolge un ambulacro interno a quello posto tra il muro d'ambito e il decagono stesso. Gli otto pilastri a sezione quadrata e le due colonne (di spoglio e con capitelli antichi) del decagono sono sormontati da pulvini altomedievali; le colonne di riuso dell'esagono impiegano solo capitelli d'età classica e, come basi, capitelli antichi rovesciati e modificati. Archi in mattoni scaricano su queste strutture e sul muro a zig-zag

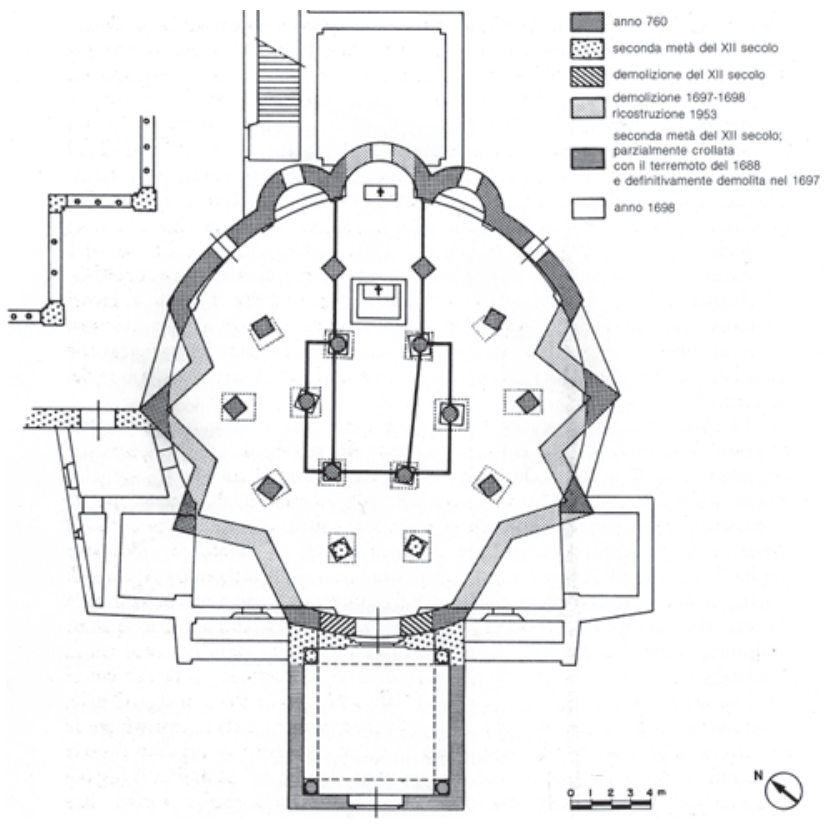

Fig. 26. Benevento, S. Sofia, pianta.

il peso delle volte quadrate, triangolari, trapezoidali che coprono i due ambulacri e quello della cupola con tiburio e della copertura a capanna, modificata solo in prossimità della facciata barocca. Il reimpiego di materiali antichi riguarda anche la muratura in opus mixtum realizzata con tufelli e laterizi di risulta (fig. 30). Va segnalato inoltre che le colonne recano i segni di restauri databili al XVIII secolo, mentre le stuccature dei pilastri dovrebbero risalire al discusso intervento (figg. 31-33) condotto fra il 1951 e il '57 dall'architetto triestino Antonino Rusconi, all'epoca Soprintendente ai Beni architettonici per la Campania: esso intese restituire la chiesa alle sue originarie forme altomedievali eliminando le superfetazioni e le trasformazioni dell'impianto prodotte soprattutto dagli interventi ricostruttivi promossi dal cardinale arcivescovo di Benevento, Vincenzo Maria Orsini (poi papa Benedetto XIII, dal 1724 al '3o) ed eseguiti in gran parte da Carlo Buratti all'indomani del distruttivo terremoto del 1688 che peraltro fu seguito dal sisma, non privo di effetti sulla chiesa, del 14 marzo $1702^{116}$. L'intervento del Rusconi, oggi non proponibile, fu accompagnato da scavi archeologici che purtroppo non vennero pubblicati, secondo un uso tuttora corrente; nonostante ciò esso risultò non privo di efficacia se, eliminando il muro ad andamento circolare col quale si era inteso ridurre a simmetria l'edificio e demolendo alcune cappelle laterali, Rusconi ricostruì, sul profilo delle fondazioni individuate in corso di scavo, il muro d'ambito a zig-zag recuperando così l'originario impianto stellare. Presupposto essenziale della ricomposizione edilizia rusconiana fu la persuasione, peraltro difficilmente confutabile, che le fondazioni a zigzag (fig. 26) individuate in corso di scavo fossero quelle della chiesa fatta edificare da Arechi II come suggerisce la formula usata nei suoi atti: «eccl(esi)a S(an)c(t)e Sophiæ quam a fundam(en)tis edificavi $\mathrm{p}$ (ro) redemptione anime mee seu p(ro) salvatione gentis nostre et patrie» ${ }^{117}$. Sull'inizio della costruzione di Santa Sofia nel 758 non possono esservi

\footnotetext{
"is E. BOSCHI, op. cit. (n. 18), n. 394 p. 34.

${ }^{116}$ Ibidem, n. 430, p. 35.

${ }^{117}$ Praecepta oblationis, novembre 774, op. cit. (n. 112); Praeceptum concessionis, novembre 774, Benevento, in palatio, op. cit. (n. 112).
} 


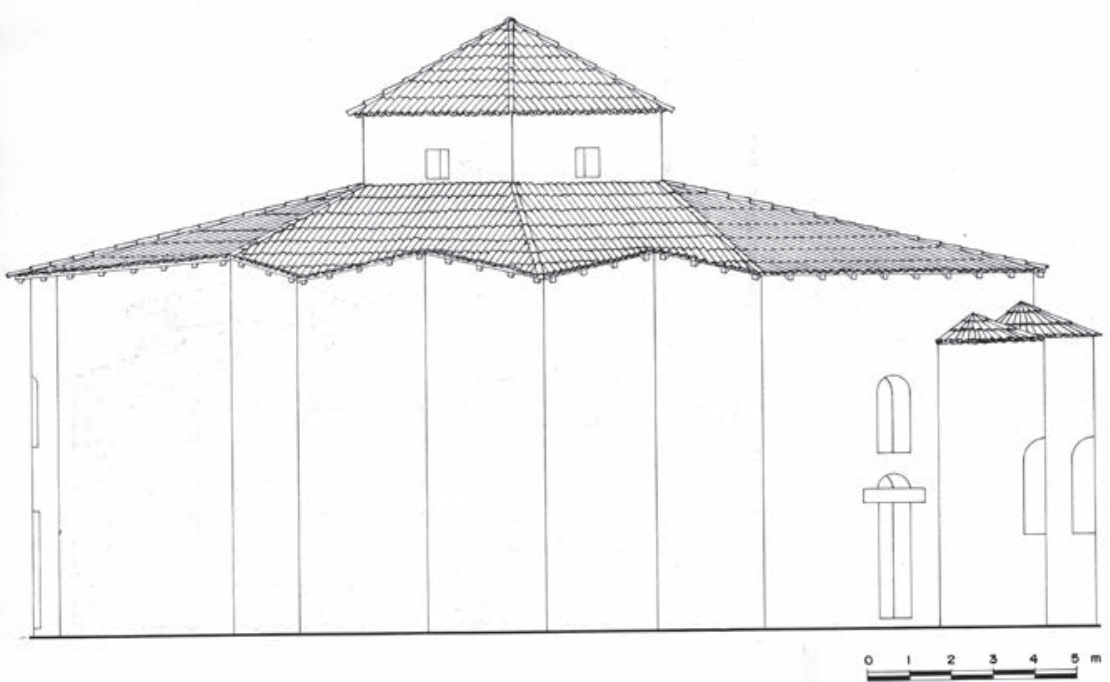

Fig. 27. Benevento, S. Sofia, prospetto.

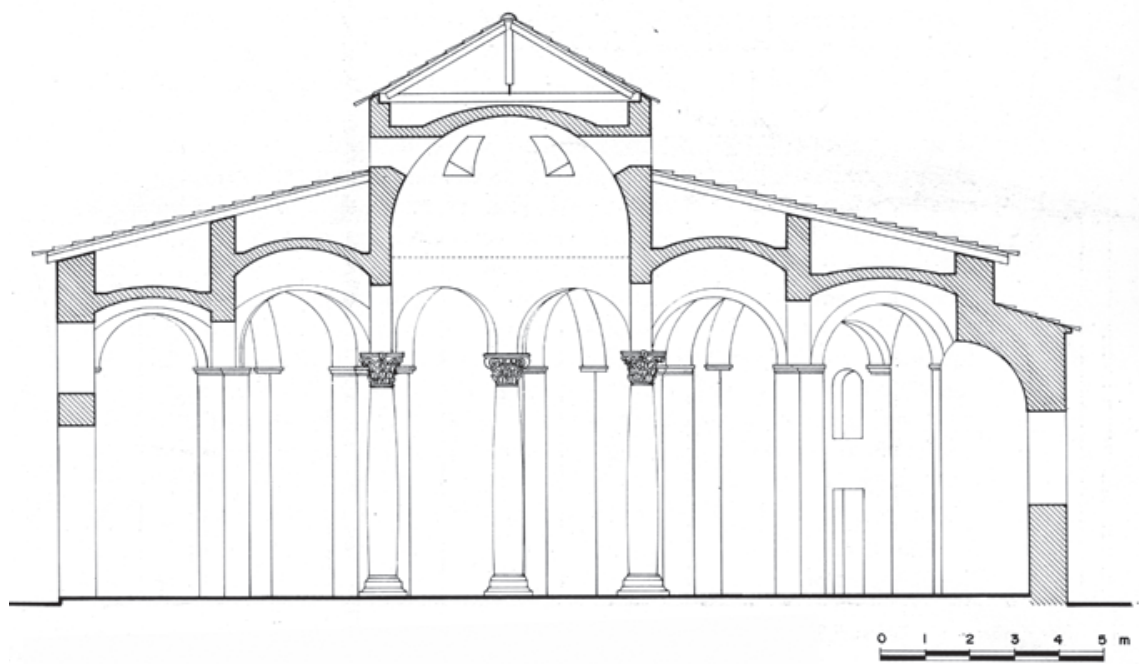

Fig. 28. Benevento, S. Sofia, sezione.

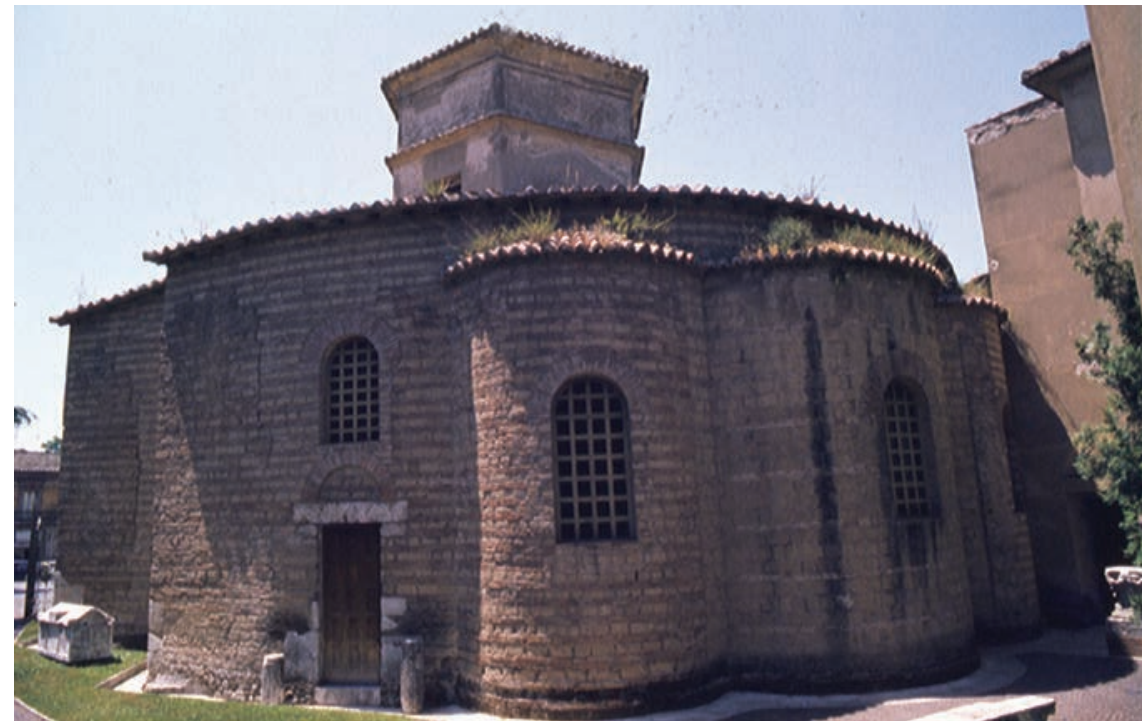

Fig. 30. Benevento, S. Sofia, esterno, muratura in opus mixtum realizzata con tufelli e laterizi di spoglio

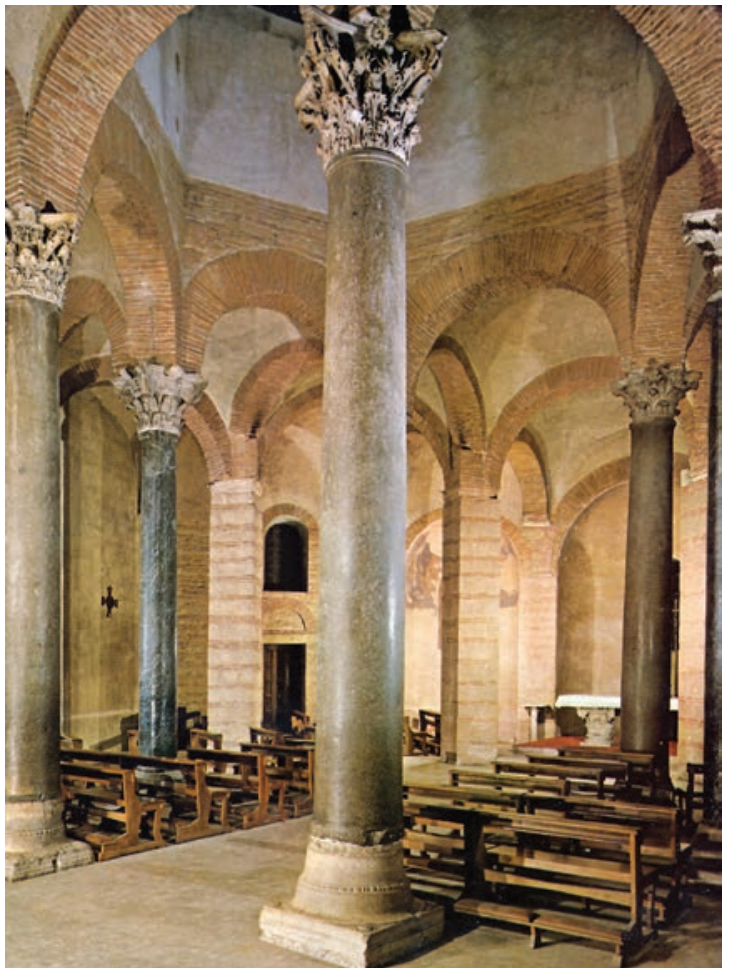

Fig. 29. Benevento, S. Sofia, interno.

dubbi perché nel maggio 760 Arechi vi tumulò in un altare le reliquie dei XII Fratelli Martiri" ${ }^{18} \mathrm{e}$ quindi doveva essere completata almeno nelle strutture, se non nella decorazione pittorica eseguita probabilmente entro il 768 , anno in cui, il 26 agosto, ebbe luogo la solenne e celebrata deposizione delle reliquie di San Mercurio"$^{19}$. Due anni circa, quanti al massimo ne sarebbero corsi tra l'inizio del ducato di Arechi e il completamento dei lavori, non sono molti. Si deve però considerare che l'edificio non è di grandi proporzioni perché il perimetro, absidi escluse, entra in una circonferenza di m 23,50 di diametro e l'altezza delle pareti alla gronda è di circa $8 \mathrm{~m}$; inoltre per la costruzione si poteva disporre con larghezza dei materiali antichi che vennero per l'appunto impiegati ${ }^{120}$.

La documentazione del restauro evidenzia un frammento della pavimentazione in opus sectile (fig. 34) non dissimile da quello rinvenuto negli scavi della cappella palatina dei Santi Pietro e Paolo di Salerno; un riscontro a tale lacerto è dato dai resti individuati nel corso dei lavori condotti nel 2009 per l'adeguamento dell'edificio ai parametri fissati dall'Unesco nell'ambito della procedura per il riconoscimento della chiesa quale patrimonio mondiale dell'umanità, procedura che ha riguardato altri sei siti italiani inseriti nella candidatura seriale Italia Langobardorum.

L'originalità dell'impianto centrale indusse Wart Arslan a proporre un nesso fra Santa So-

\footnotetext{
${ }^{18}$ Cfr. Translatio Duodecim Martyrum, G. Waitz (ed.), in MGH, op. cit. (n. 27), p.574-575 a p. 575.

${ }^{19}$ Cfr. Translatio Sancti Mercurii, op. cit. (n. 114), p. 576-580.

${ }^{120}$ Del tutto pretestuosa, oltre che priva di fondamento, la polemica sull'interpretazione delle fonti inerenti l'origine della chiesa di cui è espressione in C. LEPORE, op. cit. (n. 14), a p. 142-144, la lunga nota 478 .
} 


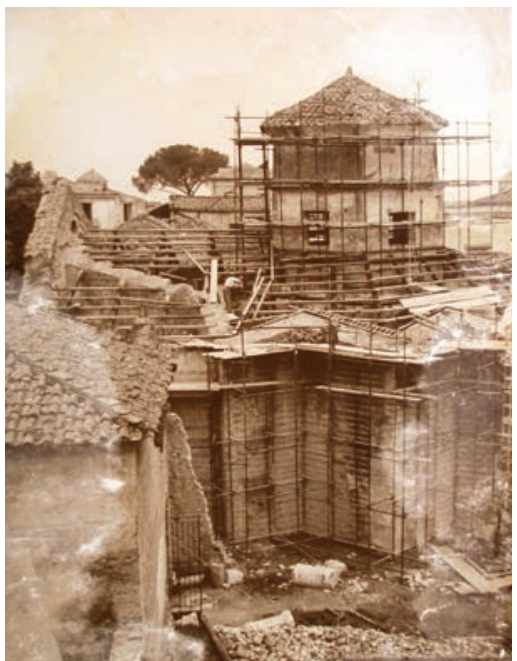

Fig. 31. Benevento, S. Sofia, lavori di restauro condotti dall'arch. Antonino Rusconi (1951-57).

fia e Santa Maria «alle Pertiche», la chiesa di Pavia che tramanda nel titulus la consuetudine di ricordare i guerrieri morti lontano dalla patria.

La chiesa era interamente affrescata, come indica la distribuzione dei superstiti frammenti. I brani più importanti del ciclo pittorico che era dedicato alle Storie di Cristo si trovano nelle absidi minori. In quella di sinistra sono rappresentate scene della Storia di San Giovanni Battista (fig. 35) mentre nell'abside destra sono le Storie della Vergine. Una vigorosa Annunciazione a Maria e la Visitazione (fig. 36) si riconoscono da sinistra a destra in quest'abside, nell'eloquente gesto dell'angelo che si volge benedicente verso il trono della Vergine e nell'abbraccio delle due donne rappresentate col nimbo circolare. La Storia di San Giovanni Battista, nell'abside sinistra, consta di due distinte scene: L'annuncio a Zaccaria (fig. 35a) della prossima nascita del Battista e il Silenzio di Zaccaria (fig. 35b) che indica ai fedeli stupefatti di essere stato privato della parola per l'incredulità all'annuncio dell'angelo. Le rappresentazioni relative a Zaccaria seguono alla lettera il testo del primo capitolo del Vangelo di San Luca ${ }^{121}$ e anche le scene dell'abside destra si succedono alle altre nel medesimo ordine del testo evangelico.

L'impegno del sovrano, quale a tutti gli effetti può essere considerato Arechi soprattutto dopo la sconfitta di Desiderio e l'assunzione del titolo di princeps (con unzione da parte del vescovo e autoimposizione della corona), rifulse nella chiesa ornata da affreschi e materiali lapidei di spoglio che le conferirono lo splendore attestato anche per la corte e il palatium beneventano: Arechi, con Adelperga, donna di notevole dottrina, viveva fra le gemme e i
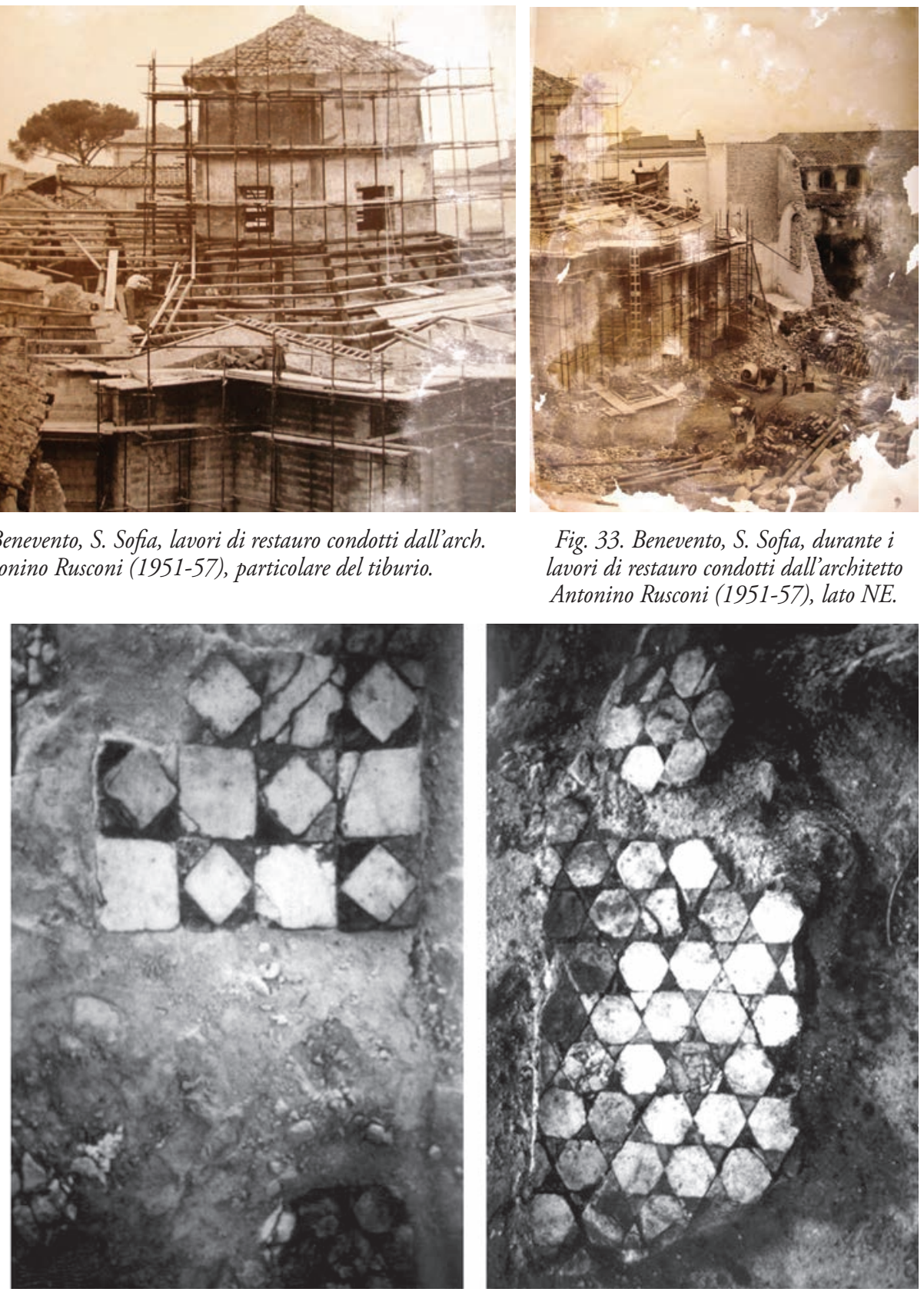

Fig. 33. Benevento, S. Sofia, durante i Lavori di restauro condotti dall'architetto Antonino Rusconi (1951-57), lato NE.

Fig. 34. Benevento, S. Sofia, pavimentazione in opus sectile.
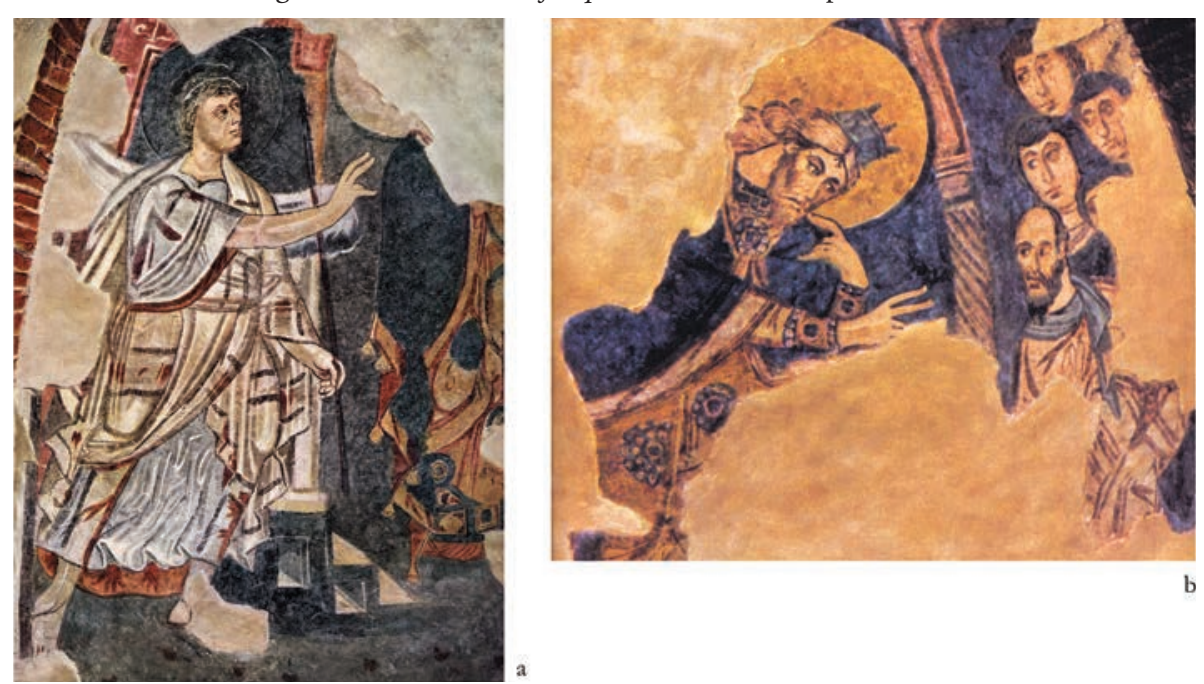

Fig. 35. Benevento, S. Sofia, affreschi raffiguranti scene della Storia di S. Giovanni Battista: $a$, Annuncio a Zaccaria; $b$, Silenzio di Zaccaria.

\footnotetext{
${ }_{121}^{21}$ Lc 1,5-22; Vangelo di S. Luca, in La Bibbia di Gerusalemme, F. Vattioni et alii (eds.), Bologna, 2002, p. 2193-2256.
} 


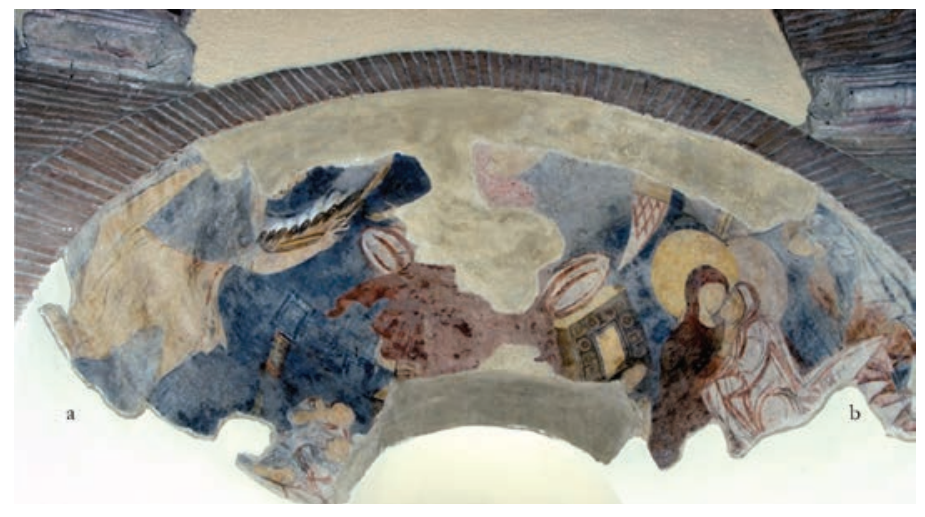

Fig. 36. Benevento, S. Sofia, affreschi con scene delle Storie della Vergine: $a$, Annunciazione a Maria; $b$, Visitazione.

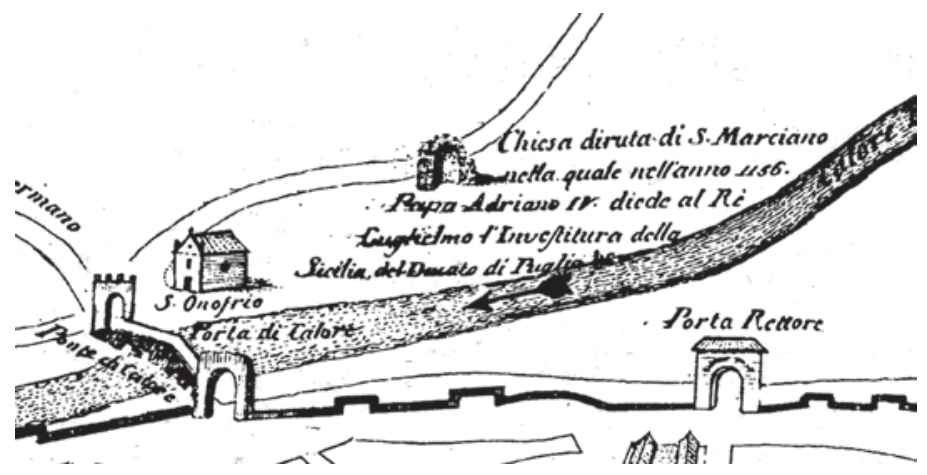

Fig. 37. Liborio Pizzella, Pianta della pontificia città di Benevento, cit., particolare con la chiesa diruta di S. Marciano e il monastero e la chiesa di S. Onofrio.

metalli preziosi venutigli dall'India, dall'Asia e dall'Etiopia' ${ }^{122}$. Si tratta delle gemme e degli ori di gusto mediorientale di cui danno ampia testimonianza non solo i rinvenimenti funerari ma soprattutto gli affreschi sofiani nei quali essi compaiono nelle raffigurazioni di Zaccaria che riceve l'annuncio e di Zaccaria muto dinanzi ai fedeli.

Il monastero che forse esisteva già prima del 774, nel 945 quando compare il suo primo abate, Orso, era ormai retto da una comunità di monaci benedettini. Prescindendo, in questa sede, dal complesso tema della sua dipendenza, vanno sottolineati l'incremento patrimoniale e il progressivo ampliamento dell'originario spazio claustrale che raggiunse l'apice nel XII secolo, come evidenziato dalla realizzazione del chiostro romanico nel quale, tuttavia, appaiono impiegati elementi di età longobarda provenienti probabilmente da un'analoga struttura di minori dimensioni risalente a quel periodo. Al prestigio morale si unì quello legato alle produzioni scrittoria e miniaturistica realizzate nello scriptorium che fiorì soprattutto fra XII e XIII secolo quando si incominciarono a registrare alcuni segni di un declino che non fu rapido in considerazione della notevole consistenza

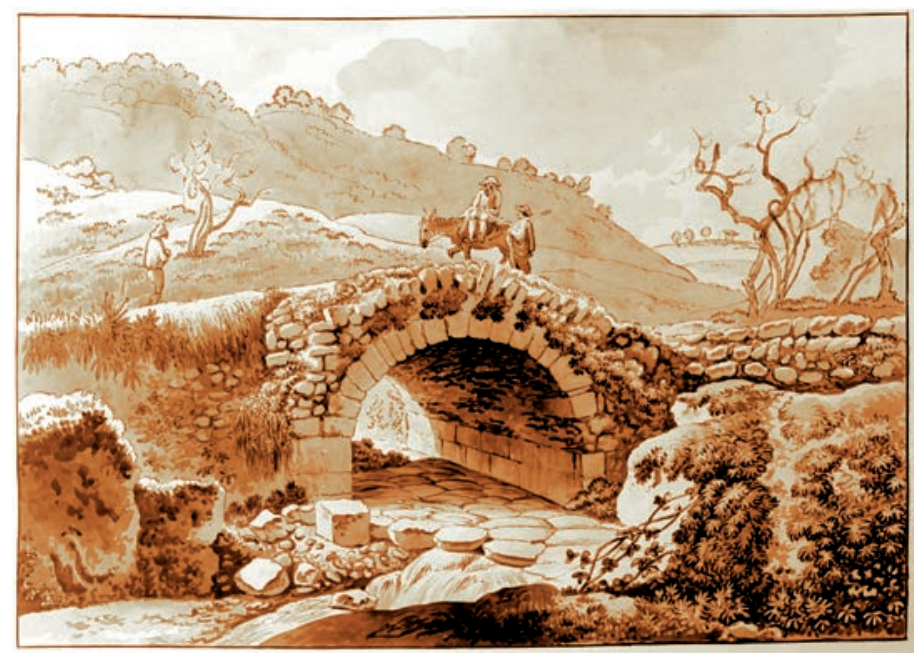

Fig. 38. Il Ponticello sulla via Traiana, disegno a seppia di Carlo Labruzzi. Roma, Accademia Nazionale di S. Luca, Biblioteca Romana "Antonio Sarti».

patrimoniale del monastero che nel 1455 fu concesso da papa Callisto III in commenda al nipote, il cardinale Rodrigo Borgia, futuro papa Alessandro VI. La lunga serie degli abati commendatari si concluse col cardinale Fabrizio Ruffo nella terza decade dell'Ottocento. Dal 1834 l'antico cenobio divenne una sede scolastica dei Fratelli delle Scuole Cristiane.

10. L'ubicazione di Sant'Ilario lungo la via Traiana che riprese il tracciato della via Minucia è comune anche ad altri edifici religiosi perché sull'importante arteria che ebbe come caput l'arco costruito in onore di Traiano sorgevano il già ricordato monastero di Santa Sofia a Ponticello (fig. 1 n. 37), fondato dall'abate Zaccaria ${ }^{123}$ durante il ducato di Romualdo II $(706-731 / 2)^{124}$ sui terreni di tale Wandulfo, proprietario di case con corti e orti, di un mulino, un bagno, un terreno e di una statio lungo l'importante arteria ${ }^{125}$ : il cenobio è documentato fino alla prima metà dell'VIII secolo mentre della chiesa si ha notizia come dipendenza sofiana ancora nei primi decenni del XII; più avanti (fig. 1 n. 37) si trovava la chiesa di San Valentino, all'altezza del ponte romano che da essa prendeva il nome, attestata da un atto di Romualdo II dell'aprile $723^{126}$, dai diplomi di Gisulfo II del luglio $745^{127}$ e di Arechi II in favore del monastero di Santa Sofia del novembre $774^{128}$ e in rapporto con il mercato che vi si teneva e che era forse una vera e propria fiera. Nella stessa direzione di San Valentino si trovava poi la chiesa di San Marco attestata anch'essa da Arechi II nel $774^{129}$.

Al di là del ponticellum (fig. 38) ma vicino ad esso («foras hanc cibitate $(\mathrm{m})$ ultra porta $(\mathrm{m})$ Aurea $(\mathrm{m})$, trans ipso ponticello fabrito»), quindi nella medesima zona del monastero di Santa Sofia a Ponticello ricordato anche da privilegi di papa Pasquale II del $1101^{130}$ e dell'antipapa Anacleto II'31 (fig. $1 \mathrm{n}$.

\footnotetext{
${ }_{122}$ Praeceptum donationum, concessionum, confirmationum, novembre 774 , op. cit. (n. 42), p. 289.

${ }^{123}$ M. ROTILI, op. cit. (n. 4), p. 115.

${ }^{124}$ S. GASPARRI, I duchi longobardi, Roma, 1978 (Studi storici, 109), p. 91-92.

${ }^{125}$ M. ROTILI, op. cit. (n. 4), p. 115; Chronicon Sanctae Sophiae, op. cit. (n. 6), p. 45.

${ }^{126}$ Ibidem, II, 12, p. 454-456, a p. 455.

${ }^{127}$ Ibidem, II, 6, p. 439-443 a p. 440.

${ }^{128}$ Praeceptum donationum, concessionum, confirmationum, op. cit. (n. 42), p. 313.

129 Ibidem, p. 319; cfr. inoltre A. ZAZO, op. cit. (n. 50), p. 6-7.

${ }^{130}$ Privilegio del 27 ottobre 1101 in Chronicon Sanctae Sophiae, op. cit. (n. 6), V, 5, p. 636-644, a p. 638.

${ }^{131}$ Chronicon Sanctae Sophiae, op. cit. (n. 6), V, 11, Privilegium papae dell'8 febbraio 1131, p. 654-662, a p. 656; P. F. Kehr, W. Holtzmann (eds.), op. cit. (n. 9), p. 93-94.
} 


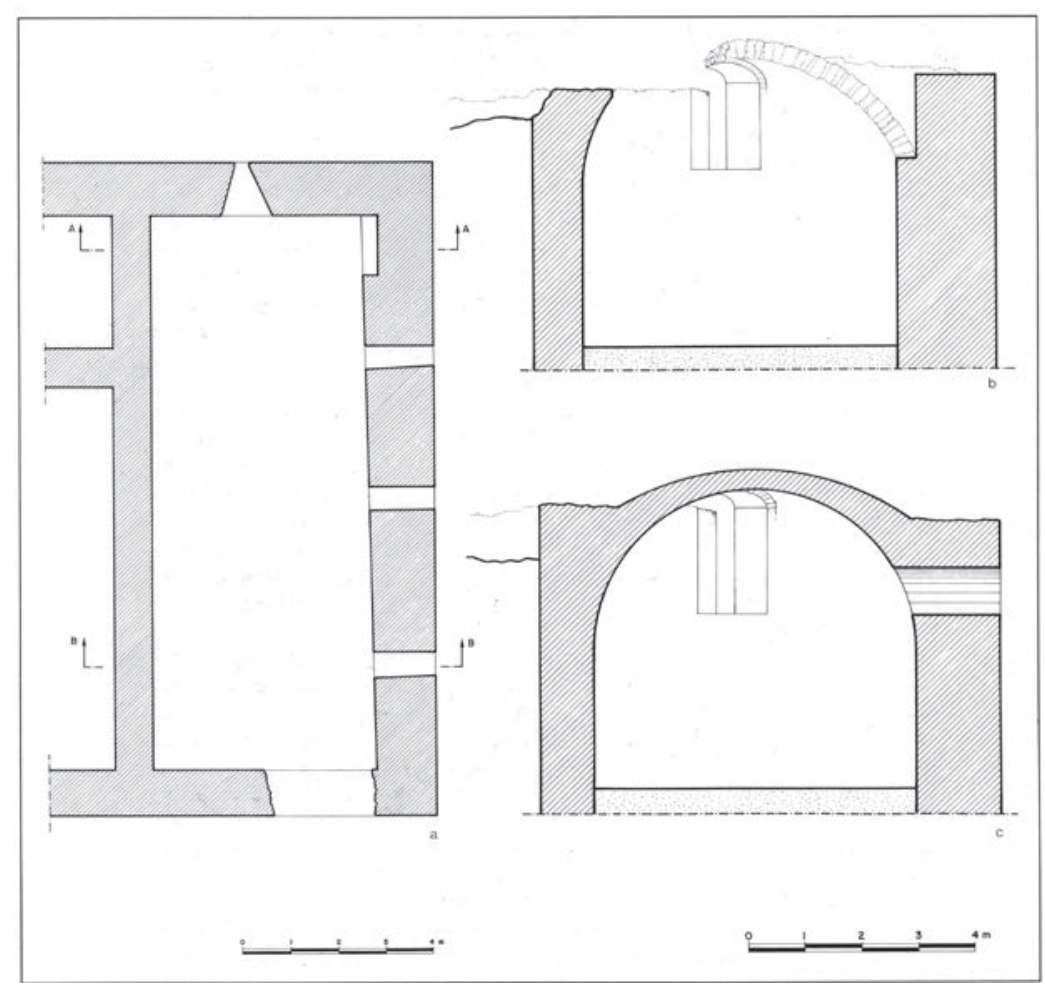

Fig. 39. Benevento, S. Angelo a Piesco: a, pianta; $b$, sezione A-A; $c$, sezione B-B. 40) era la chiesa di San Michele Arcangelo presso la quale da Pandolfo III e Landolfo VI nel 1050 venne autorizzata la ricordata costruzione di uno Xenodochio in sostituzione di quello, ormai in rovina, di San Benedetto ad Xenodochium ${ }^{132}$. Questa chiesa dedicata all'Arcangelo che nel 1628 risulta diruta $^{133}$ è evidentemente diversa da quella di San Michele Arcangelo ad Olivolam ricordata dal diploma di Ottone III del 22 aprile $974^{134}$, da un privilegio di papa Gregorio VII dell'n dicembre $1084^{135} \mathrm{e}$ da un atto del $1^{\circ}$ ottobre $1175^{136}$.

Stando alle indicazioni dei due documenti e del citato privilegio di Anacleto II ${ }^{37}$ la chiesa ad Olivolam corrisponde a quella di Sant'Angelo a Olivola sopra Pantano, mentre risulta diversa dalla chiesa di Sant'Angelo a Piesco riconosciuta nella costruzione che è sulla sommità di un colle non lontano dalla contrada Pantano e dal punto di arrivo della via Latina e della via dell'alto Sannio. Nel privilegio di papa Pasquale II del $1101^{138}$ figurano le chiese ricordate dai citati atti di Ottone III, Gregorio VII e Anacleto II, quindi compare anche la chiesa di Sant'Angelo a Piesco che è distinta da quella di Sant'Angelo a Olivola. La posizione dell'edificio e le tracce di una probabile recinzione dell'area inducono a credere che facesse parte di un nucleo fortificato posto a presidio di importanti strade d'accesso alla città.

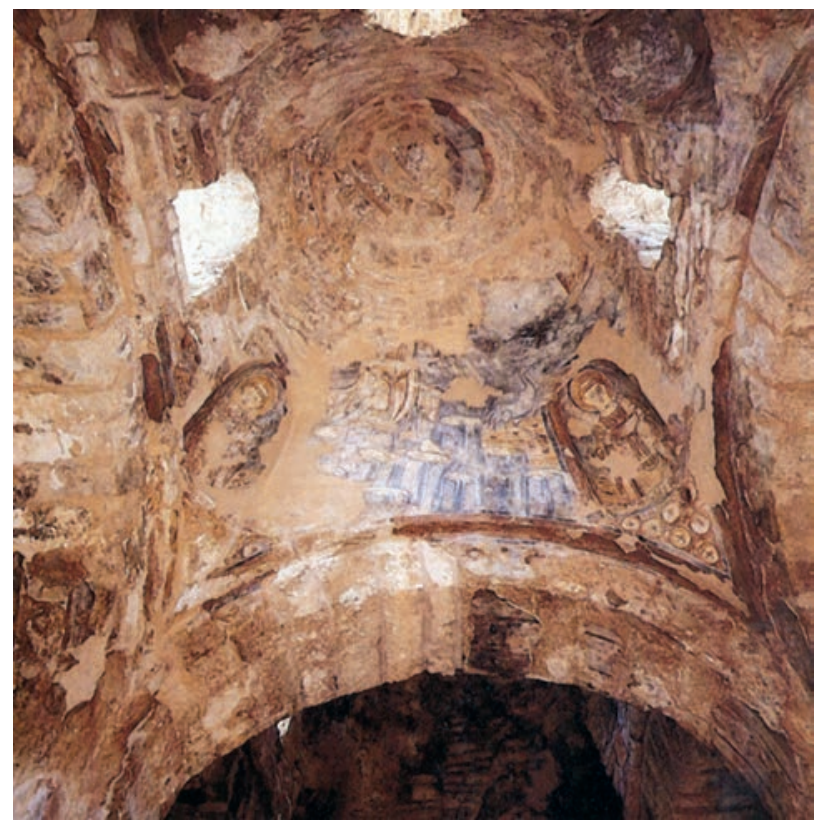

Fig. 40. Fasano (Bari), il tempietto di Seppannibale.

L'inedita costruzione è un'aula unica (fig. 39) conclusa da una da una parete priva di abside recante un arco al quale si può attribuire solo una funzione di scarico. Alla parete d'ambito sinistra aderisce un corpo di fabbrica di difficile identificazione che ne occlude le piccole aperture in alto; il muro perimetrale destro presenta invece tre finestre integre e fori pontali a sezione quadrangolare. L'ingresso era probabilmente nella parete opposta a quella con arco e monofora, dove un crollo ha creato un varco. Nella medesima zona di Sant'Angelo a Olivola e di Sant'Angelo a Piesco che, in base a quanto detto non dovevano essere lontane, figura nel (il riferimento è al sopra menzionato privilegio di papa Pasquale II) una chiesa di San Mercurio a Olivola mentre a non grande distanza, in contrada San Vitale, doveva essere l'omonima chiesa di cui parlano vari diplomi, da quello di Ottone I dell'aprile $972^{139}$ fino a quello dell'antipapa Anacleto II datato 8 febbraio $113^{140}$.

Tra gli edifici posti non lontano dall'area considerata si deve registrare il monastero maschile di San Benedetto a Pantano che fu a lungo una dipendenza cassinese (poi dipese da Santa Sofia di Benevento) ${ }^{141}$. Menzionato dal falso diploma del 12 febbraio 798, col quale Carlo Magno ne confermò a Montecassino il possesso ${ }^{142}$, risulta appartenere all'abbazia per effetto della donazione effettuata fra il 764 e il 771 dal nobile beneventano Leone $e^{143}$. Documentato da vari atti fra i quali il più volte citato privilegio di Anacleto II dell'8 febbraio 1131, compare nel diploma dei principi Pandolfo II,

\footnotetext{
${ }_{132}$ Chronicon Sanctae Sophiae, op. cit. (n. 6), III, 50, p. 580-585, a p. 580-582. cura ma non so di chi sia».

${ }^{134}$ Chronicon Sanctae Sophiae, op. cit. (n. 6), VI, 1, p. 587-593, a 589.

${ }_{135}$ Chronicon Sanctae Sophiae, op. cit. (n. 6), p. 624-630, a 625.

${ }^{136}$ ASP-BN, Fondo S. Sofia, XXXVI, 13.

${ }^{137}$ Chronicon Sanctae Sophiae, V, 11, Privilegium papae dell'8 febbraio 1131, p. 654-662, a p. 656.

${ }^{138}$ Privilegio di papa Pasquale II [Chronicon Sanctae Sophiae, op. cit. (n. 6), p. 636-644, a 638].

${ }_{139} \mathrm{Ibidem}, \mathrm{VI}, 1, \mathrm{p} .587-593$, a p. 589.

${ }^{140} \mathrm{Ibidem}, \mathrm{V}, 10$, p. 654-662, a p. 656.

${ }^{141} \mathrm{Cfr}$. H. BLOCH, Monte Cassino in the middle ages, II, Roma, 1986, p. 686-687.

${ }^{142}$ Diplomata Karolina, MGH, op. cit. (n. 27), 1, Berolini, 1956, p. 77-478, a p. 369.

${ }^{143}$ LEONIS OSTIENSIS CMC, op. cit. (n. 40), I, 10, p. 41.
}

${ }_{133}$ Index Pacilli, op. cit. (n. 3), f. 24v: «Santo Agnilo a ponticello. Questa chiesa sta derelitta et abbandonata et è quasi diruta, non ci è persona che ne habia 


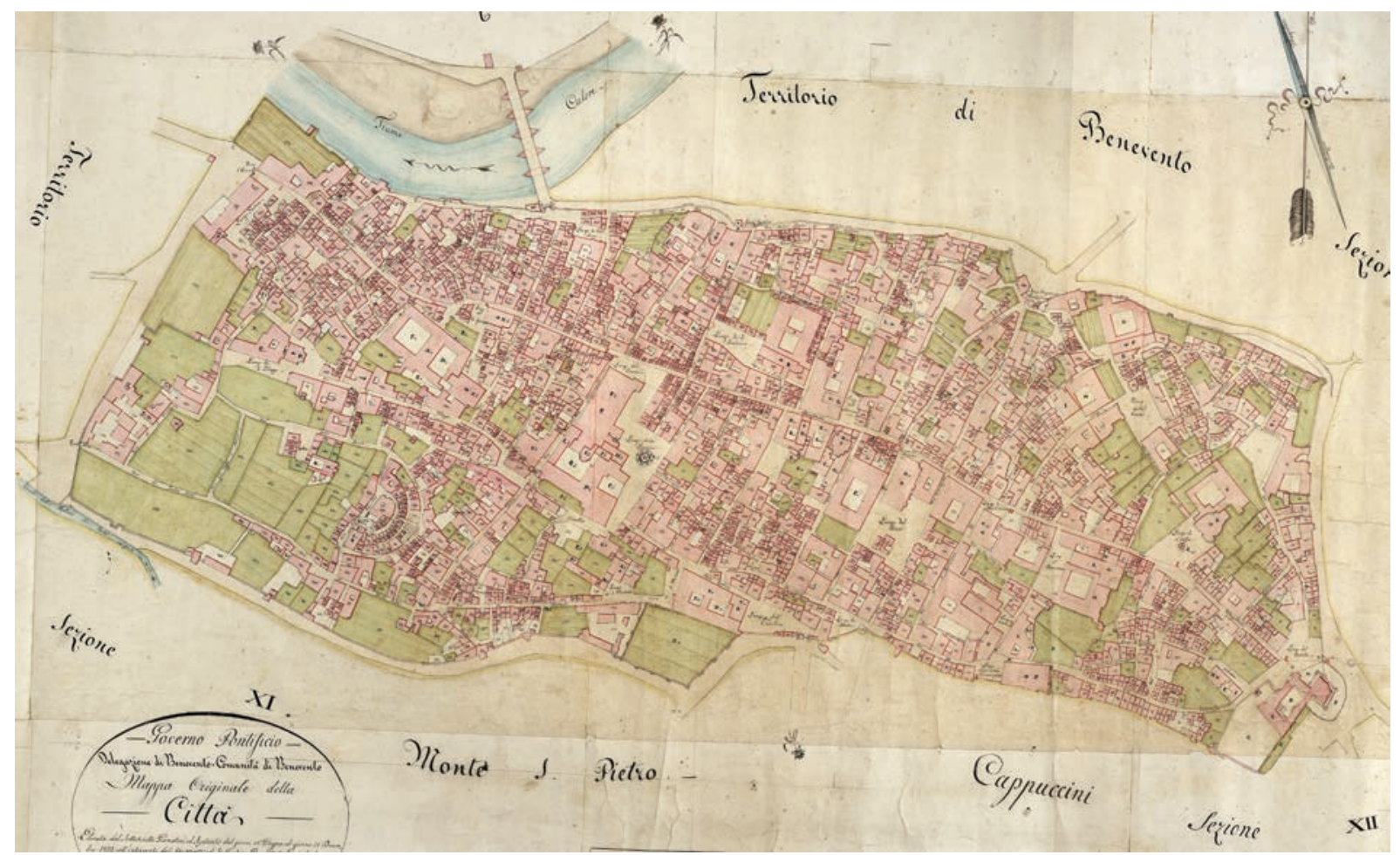

Fig. 42. Luigi Mazarini, Mappa originale della città di Benevento, Roma Archivio di Stato, CPG, 277 n. 1.

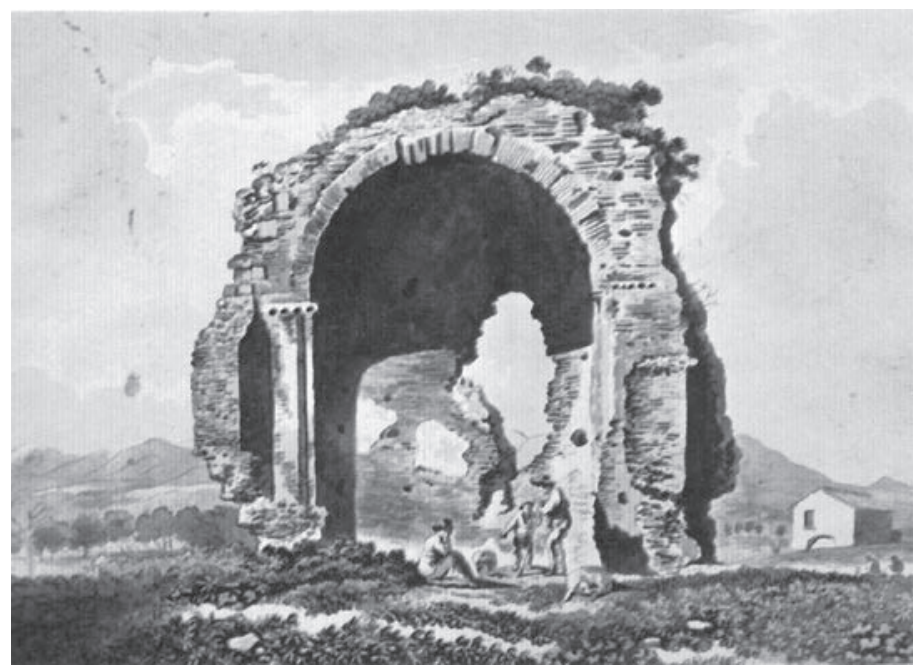

Fig. 41. La chiesa di s. Marciano, disegno a seppia di Carlo Labruzzi. Roma, Accademia Nazionale di S. Luca, Biblioteca Romana «Antonio Sarti».

Landolfo V e Pandolfo III del 18 dicembre 1012 nel quale si fa riferimento ad «Amatum vene(rabilem)abb(atem) ecclesie Sancti Benedicti, que constructa est extra hanc Benev(entanam) civita|tem iuxta fluvio Caloris»» ${ }^{14}$ dal quale traspare l'autonomia conseguita. Se ne perdono le tracce non molti anni dopo. Fuori Port'Aurea nel novembre 1110 sono attestate le chiese di San Teodoro e di San Girolamo, tra loro vicine ${ }^{145}$, ma probabilmente di età longobarda.

10. Presso la città, non lontano da Porta Rettore e dal monastero urbano di San Paolo già preso in considerazione esistevano nell'VIII secolo le chiese di Santo Stefano foris civitatem e di San Marciano sul Calore (fig. 1 n. 39; 37, 41). Mentre la prima ricorre nel diploma di Arechi II del novembre $774^{146}$, San Marciano, per la quale vennero utilizzate le strutture di un tempio pagano, forse quello dedicato a Ercole, è attestata già nel 724 dal citato diploma di Romualdo II. Documentata varie volte, da un documento del luglio 1138 viene messa in relazione con un guado per carri esistente giusto sotto la chiesa che era oltre il fiume ${ }^{147}$.

Più a occidente, alta lungo il medesimo fiume, nell'area del complesso romano in cui venne ricavata quella dei Santi Quaranta (fig. 1 n. 32), sorgeva la chiesa di San Lorenzo (fig. 1 n. 24). Documentata lungo il fiume Calore nel settembre $1086^{148}$ e nel maggio $1157^{149}$ esisteva già nell'VIII secolo come attesta l'intitolazione della porta urbica ${ }^{150}$.

La chiesa dei Santi Quaranta dedicata ai quaranta martiri di Sebaste ${ }^{151}$, venne ricavata riutilizzando una piccola porzione del grande edificio del II-I secolo a. C. che ne porta il nome e che connota l'area di Cellarulo, esclusa dalla città romana nel IV in rapporto alla ristrutturazione urbana e alla

\footnotetext{
${ }^{144}$ Le più antiche carte del Capitolo, op. cit. (n. 12), 30, p. 89-93 a p. 91.

${ }^{145}$ ASP-BN, Fondo S. Sofia, XXXIV, 4.

${ }^{146}$ Praeceptum donationum, concessionum, confirmationum, op. cit. (n. 42), p. 301-302.

${ }^{147}$ ASP-BN, Fondo S. Sofia, VIIl, 36.

${ }^{148}$ ASP-BN, Fondo S. Sofia, XXXVI, 4.

149 Privilegio di Enrico, arcivescovo di Benevento, in Le più antiche carte del Capitolo, op. cit. (n. 12), n. 77, p. 226-228, a p. 227: «ecclesiam Sancti Lauren | [tii pro]pe [m]enia [civitatis] Ben[ev]ent[ane] super rivam fluvii Caloris edificatam».

${ }^{150}$ Praeceptum donationum, concessionum, confirmationum, op. cit. (n. 42), p. 330.

${ }^{151}$ A. AMORE, s.v., Sebastia, XL Martiri di, in Bibliotheca sanctorum, XI, Città del Vaticano, 1968, col. 768-771; M. FALLA CASTELFRANCHI, Pitture "iconoclaste" in Italia meridionale? Con un'appendice sull'oratorio dei Quaranta Martiri nella catacomba di Santa Lucia a Siracusa, in Bisanzio e l'Occidente: arte, archeologia, storia. Studi in onore di Fernanda de' Maffei, Roma, 1996, p. 409-425, a p. 418-419.
} 
costruzione delle nuove mura urbiche ${ }^{152}$ : il toponimo Cellarulo deriverebbe dalla funzione di cellarium per lo stivaggio di merci attribuita ai monumentali resti del complesso ${ }^{153}$ detto appunto dei Santi Quaranta dal titolo della chiesa che fu in esso impiantata probabilmente tra il 1119 e gli anni antecedenti il 1198 visto che non è citata nel liber preceptorum Beneventani monasterii Sanctae Sophiae la cui compilazione fu portata a termine entro l'agosto $1119^{154}$, mentre compare nell'Obituarium S. Spiritus, iniziato nel 1198 e integrato sino alla fine del XIV secolo, nel quale è registrato il decesso di «Raymundus quod fuit abbas sanctorum quadraginta» $»^{155}$.

Nei pressi del ponte di età romana detto di Sant'Onofrio ${ }^{156}$ sorgeva l'omonimo monastero documentato almeno dal XII secolo (fig. 1 n. 22; 37) ${ }^{157}$; la vicina chiesetta del XVIII che ne costituiva il residuo venne abbattuta nella prima parte del XX secolo ed è nota grazie ad

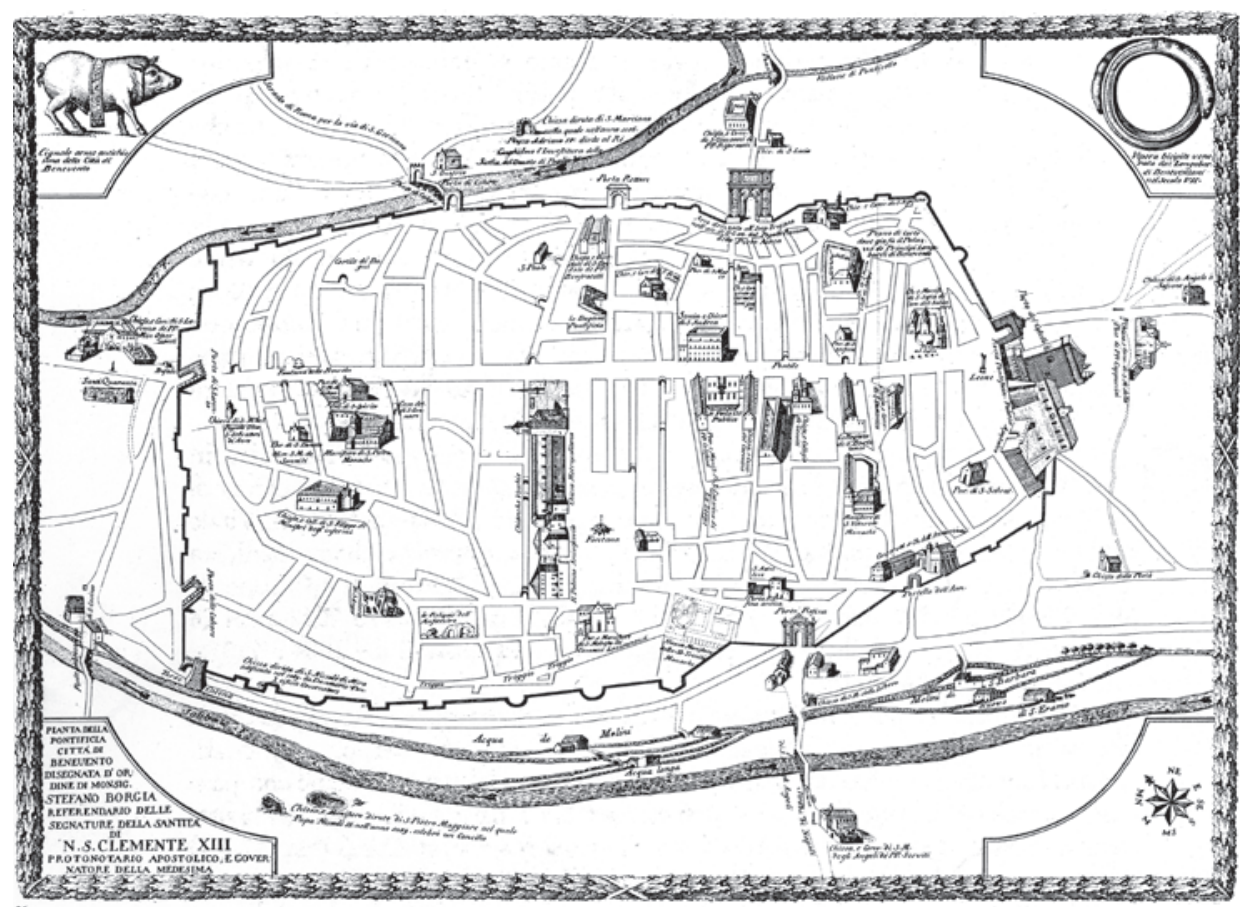
una fotografia probabilmente degli anni Venti o Trenta.

Sul versante meridionale, lungo la via Appia in arrivo da Capua, poche centinaia di metri prima del Ponte Leproso (fig. 1 n. 30), al di là del fiume Sabato sorgeva il monastero femminile di San Pietro fuori le mura (fig. 1 n. 29), fondato da Teoderada ${ }^{158}$, la consorte del duca Romualdo I che a Canosa di Puglia fece erigere il sacello di San Sabino ${ }^{159}$. Procedendo lungo la strada verso la città, appena passato il Ponte Leproso si trovava la chiesa di San Cosma (fig. 1 n. 31) delle cui strutture nulla rimane nell'edificio di età moderna dedicato ai Santi Cosimo e Damiano ${ }^{160}$.

Fig. 43. Liborio Pizzella, Pianta della pontificia città di Benevento, cit.

11. Nella Civitas nova, ove l'ecclesia Sancti Bartholomei in thermis trae il nome da un edificio termale (fig. 1 n. 35), si registrano l'ecclesia Sancti Nicolay Turris Paganae (fig. 1 n. 26), la chiesa di San Modesto, costruita tra il 758 e il 774, cui venne annesso un cenobio maschile entro l'852 (fig. $1 \mathrm{n}$. 18), il monastero dei Santi Lupolo e Zosimo (fig. 1 n. 20), le chiese dei Santi Filippo e Giacomo (fig. 1 n. 23), di Santa Tecla e San Secondino (fig. 1 n. 23) e due chiese attestanti mestieri (fig. 1 nn. 19, 15): San Nazzaro de lutifiguli e San Giovanni de fabricatoribus ${ }^{161}$.

La vicenda di San Modesto che subì gravissimi danni in seguito ad un attacco dei Saraceni degli anni fra l'857 e

\footnotetext{
${ }^{152}$ Il complesso monumentale di Cellarulo è stato diversamente datato fra la tarda età repubblicana e la fine del II-inizi del III d.C. ma la tecnica muraria impiegata, l'opera quasi reticolata di calcare, particolarmente attestata tra l'ultimo quarto del II e il I a.C. quando prese a diffondersi l'opus reticulatum, potrebbe orientare la datazione al II-I a.C. [C. EBANISTA, Il complesso archeologico dei Santi Quaranta. Archeologia e storia, in M. Rotili (ed.), Benevento nella tarda antichità. Dalla diagnostica archeologica in contrada Cellarulo alla ricostruzione dell'assetto urbano, Napoli, 2006, p. 179-210]. Ampliato e rimaneggiato varie volte, il complesso ha suscitato interpretazioni contrastanti tanto da essere considerato di volta in volta un complesso termale, un criptoportico o un foro boario o ancora il santuario di un'Atena, originariamente Ilias, quindi ribattezzata Berecyntia, secondo un'ipotesi suggestiva ma priva di riscontri archeologici per cui non si può escludere che quest'ultimo tempio sorgesse nel foro [M. ROTILI, op. cit. (n. 4), p. 5o, TBL, 9]. Su questi problemi cfr. M. ROTILI, Cellarulo e Benevento: la formazione della città tardoantica, in M. Rotili (ed.), Benevento nella tarda antichità, op. cit., p. 9-88.

${ }^{153}$ A. MEOMARTINI, I monumenti e le opere d'arte della città di Benevento [...], Benevento, 1889-95, p. 333-334.

${ }^{154}$ Chronicon Sanctae Sophiae, op. cit. (n. 6), p. 1.

${ }^{155}$ A. ZAZO, op. cit. (n. 64), p. 23.

${ }^{156}$ Il ponte è quello che Luigi Vanvitelli, 'Primo architetto' dei Borboni di Napoli dal 1751 al 1773, fu chiamato a restaurare nel 1766 e nel 1767 (M. ROTILI, La necropoli longobarda di Benevento, Napoli, 1977, p. 28-29, 71 note 84-87) e che solo nel 1777, quattro anni dopo la sua morte, sarebbe stato ricostruito su suo progetto a breve distanza dal ponte romano (fig. 1 n. 22) che egli aveva considerato rifatto «nei secoli oscuri e poco culti»: a sei arcate con luci diseguali, sorrette da sette piloni in posizione anomala rispetto al flusso delle acque (e in cinque dei quali altrettante aperture a nicchia dovevano facilitarne il deflusso), il ponte presentava «la tortuosa direzione irregolare dell'angustissimo passaggio [...] a biscia irregolare» [M. ROTILI, op. cit. (n. 4), p. 28-29, 70-71 note 81, 84-86]. Nell'ambito dei lavori di sistemazione dell'alveo fluviale condotti dal 1956-57 con la costruzione dei nuovi argini, è stato sostituito da uno moderno a tre arcate: si intese così prevenire alluvioni come quella del 2 ottobre 1949 le cui conseguenze furono aggravate dall'effetto diga svolto dal ponte vanvitelliano a sei arcate. La costruzione di uno scolmatore a monte della città avrebbe potuto evitare l'abbattimento dell'opera del Vanvitelli di cui si conservano le basi dei piloni fra le arcate della struttura attualmente in esercizio; una cinquantina di metri a valle di quest'ultimo è possibile rilevare peraltro i resti delle pile di fondazione del ponte di Sant'Onofrio individuate anche dall'aereofotointerpretazione.

${ }^{157}$ A. ZAZO, op. cit. (n. 64), p. 6, 10.

${ }^{158}$ PAULI DIACONI Historia Langobardorum, in MGH, op. cit. (n. 27), L. Bethmann, G. Waitz (eds.), VI, 1; P.F. Kehr, W. Holtzmann, op. cit. (n. 9), p. 105-106. 159 Cfr. M. FALLA CASTELFRANCHI, G. BERTELLI, Canosa di Puglia fra Tardoantico e Medioevo, Roma, 1981, tav. LXXVIII.

${ }^{160}$ Atto dell'agosto 990, P.M. Tropeano (ed.), Codice diplomatico verginiano, Montevergine, 1977, n. 13, p. 49-50, a p. 49; M. ROTILI, op. cit. (n. 4), p. 15-16, 18, 157-162 e passim.

${ }^{161}$ M. ROTILI, op. cit. (n. 4), p. 154-155.
} 
l'862 e che patì le conseguenze degli attacchi di Federico II del 1240 e degli inizi del 1250, si concluse nei primi anni del XVI secolo. Seriamente danneggiato dai terremoti del 1688 e del 1702, fu rapidamente ricostruito tanto che il 26 aprile 1711 l'arcivescovo Orsini poté consacrarne la chiesa. Sede dei Canonici Lateranensi fino al 1818 circa, quando l'arcivescovo Domenico Spinucci l'affidò a sacerdoti secolari devolvendo le rendite al Seminario diocesano, fu in parte ceduto nel 1821 ai Padri Redentoristi e in seguito divenne la sede dell'officina della Società Elettrica del Sannio (mentre una parte era stata destinata alla residenza del parroco). I bombardamenti del settembre 1943 distrussero l'edificio il cui titolo è stato attribuito ad una chiesa parrocchiale costruita negli anni Cinquanta nel Rione Libertà; consistenti resti del monastero sono tuttavia esplorabili a valle di via Gaetano Rummo, essendo stati parzialmente liberati dalle macerie. Nella parte posteriore di una casa tardomedievale di non piccole dimensioni cui si accede da via Mario La Vipera possono vedersi poi archi in pietra e laterizi su pilastri molto robusti, probabilmente riferibili a un edificio annesso alla chiesa dei Santi Filippo e Giacomo (fig. 1 n. 23). Poiché i monaci di Montevergine cominciarono a officiare questo luogo di culto tra il giugno 1144 e il giugno 1145 allora dovette sorgere il monastero (il cui primo abate sarebbe stato il beneventano Giovanni Pantasia) esistito fino alla metà del Seicento ${ }^{162}$, le strutture individuate, se a questo si riferiscono, non possono essere considerate come documento edilizio della tarda età longobarda a meno che non abbiano fatto parte di una fabbrica più antica del cenobio verginiano che effettivamente risulta documentata alla fine del X secolo ${ }^{163}$. Dopo un lungo periodo di prosperità, dalla seconda metà del Cinquecento il declino del monastero fu molto rapido tanto che nel secolo successivo continuò ad avere scarso rilievo sebbene fosse stato ripristinato il priorato.

Il monastero maschile intitolato ai Santi Lupolo e Zosimo (fig. 1 n. 20) è documentato per la prima volta nel febbraio 949 dal «[M] emoratorium factum a me Iohanne abb(ate) monasterii sanctorum Lupuli et Zosimi, quod edificatum est infra nobam $\mathrm{B}<$ eneventanam $>\mid$ civitatem» ${ }^{164}$. La con- cessione dei principi Pandolfo I e Landolfo IV del 7 ottobre 980 (?) ${ }^{165}$, relativa alla facoltà di erigere nell'ambito dei possessi del monastero, presso la località di Ponte di Santa Anastasia (attuale comune di Ponte), una fortificazione in cui abitino gli uomini liberi che lavorano nelle terre del monastero stesso, i quali presteranno a quest'ultimo i servizi finora dovuti al sacro Palazzo, fa evidente riferimento al fenomeno dell'incastellamento del territorio per scopi essenzialmente produttivi e testimonia la consistenza patrimoniale del cenobio: estese proprietà erano nei territori di Alife, Telese e Boiano. Il suo scriptorium svolse nell'XI secolo un'attività molto significativa testimoniata da codici miniati famosi come il ms 4 dell'abbazia di Cava dei Tirreni Leges Langobardorum, Capitularia regum Francorum. Agli inizi del XV secolo ebbe inizio il declino tanto che nel 1443 papa Eugenio IV ne decretò la soppressione annettendo le rendite alla mensa del Capitolo metropolitano. Nel 1579 la chiesa era già diruta e fu profanata prima del 1628 per essere adibita ad abitazione. Alla fine del Seicento il sito fu destinato a pubblico cimitero e dopo il sisma del 1688 l'arcivescovo Orsini vi fece erigere una nuova chiesa che fu consacrata nel 1696 sotto il titolo di San Lupo e che ha subito i gravi bombardamenti del settembre 1943 .

Edifici religiosi documentati verso la fine dell'età longobarda sono le chiese di Santa Tecla e San Secondino ricordate per la prima volta rispettivamente nel $1022^{166}$ e nel $1053^{167} \mathrm{e}$ la chiesa di San Giovanni Battista a Porta Foliarola attestata nel 1012 ma probabilmente più antica ${ }^{168}$ (fig. 1 n. 23).

Nel quadro riassuntivo e certo non esaustivo che si è tentato di delineare vanno ancora inserite almeno le ecclesiae $S$. Nicolay Turris Pagane, S. Nicolay de Rodenandi, S. Nicolay in Urbili e $S$. Marie rotunde: l'ultima sorgeva in prossimità di Port'Arsa mentre le altre si trovavano a breve distanza nei pressi della Torre della Catena (fig. 1 n. 21): in particolare, la Turris Pagana corrisponde alla torre distante poche decine di metri da quest'ultimo fortilizio ed è quella che ingloba un arco di porta romana o tardoantica (fig. 1 n. 21).

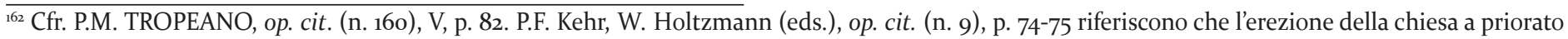
verginiano risale al 1157 .

${ }^{163}$ P.M. TROPEANO, op. cit. (n. 16o), II, p. 3-6.

${ }^{164}$ Le più antiche carte del Capitolo, op. cit. (n. 12), 11, p. 32-34, a p. 33.

${ }^{165}$ Ibidem, 21, p. 64-67, a p. 66.

${ }^{166}$ Memoratorium locationis, in P.M. TROPEANO, op. cit. (n. 155), V, n. 27, p. 103-104.

${ }^{167}$ Le più antiche carte del Capitolo, op. cit. (n. 12), 42, p. 134-138, a p. 137.

${ }_{168}$ Ibidem, 35, p. 109-111, a p. 110.
}

* Referenze delle illustrazioni: Figg 1-2, 5-9, 13-17, 25, 29, 31-34 (da Archivio ROTILI); Figg. 3-4 (da L. TOMAY, op. cit. (n. 3), figg. 10-11 a, b); Fig. 10 (da C. LEPORE, op. cit. (n. 14), tav.); Figg. 11, 37, 43 (da S. BORGIA, op. cit. II (n. 9),fig. 1, p.1); Figg. 12, 17-23, 27-30, 35-39 (da M. ROTILI, op. cit. (n. 4), figg.11, 28, 45, 61, 63-67, Tavv. XVIII, XXXVIII-XXXIX, XLIX n. 4); Fig. 24 (da Biblioteca Apostolica, Città del Vaticano); Fig. 40 (da G. BERTELLI, Il tempietto di Seppannibale in territorio di Fasano, in V. L’ABBATE, Società, cultura, economia nella Puglia medievale: atti del Convegno di Studi, Bari, 1985, pp. 235-276, fig. 7); Fig. 42 (da ARCHIVIO DI STATO, ROMA, concessione a pubblicare del Ministero per i Beni e le Attività culturali, ASR n. 13/2006). 